\title{
1 Sustainable Thorium Nuclear Fuel Cycles: A Comparison of Intermediate and Fast
}

\section{Neutron Spectrum Systems}

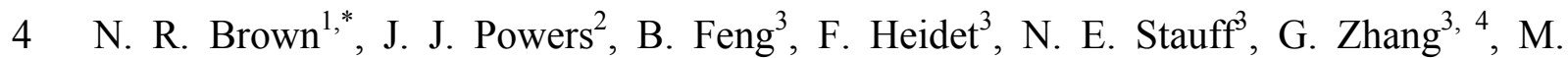

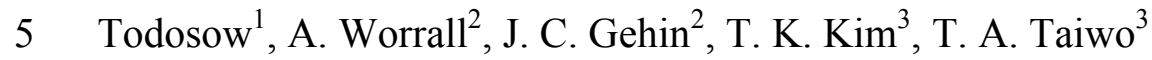

7 1) Brookhaven National Laboratory, Upton, NY, United States

8 2) Oak Ridge National Laboratory, Oak Ridge, TN, United States

9 3) Argonne National Laboratory, Argonne, IL, United States

10 4) Intern from University of California at Berkeley

11 * Corresponding author: nbrown@bnl.gov, +1 (631) 3445204 (Phone)

\section{Abstract}

This paper presents analyses of possible reactor representations of a nuclear fuel cycle with continuous recycling of thorium and produced uranium (mostly U-233) with thorium-only feed. The analysis was performed in the context of a U.S. Department of

Energy effort to develop a compendium of informative nuclear fuel cycle performance data. The objective of this paper is to determine whether intermediate spectrum systems, 
26 having a majority of fission events occurring with incident neutron energies between 1

$27 \mathrm{eV}$ and $10^{5} \mathrm{eV}$, perform as well as fast spectrum systems in this fuel cycle. The

28 intermediate spectrum options analyzed include tight lattice heavy or light water-cooled

29 reactors, continuously refueled molten salt reactors, and a sodium-cooled reactor with

30 hydride fuel. All options were modeled in reactor physics codes to calculate their lattice

31 physics, spectrum characteristics, and fuel compositions over time. Based on these

32 results, detailed metrics were calculated to compare the fuel cycle performance. These

33 metrics include waste management and resource utilization, and are binned to

34 accommodate uncertainties. The performance of the intermediate systems for this self-

35 sustaining thorium fuel cycle was similar to a representative fast spectrum system.

36 However, the number of fission neutrons emitted per neutron absorbed limits

37 performance in intermediate spectrum systems.

\section{Introduction}

41 The U.S. Department of Energy (U. S. DOE) Fuel Cycle Technologies (FCT) Program

42 Office has recently completed an Evaluation and Screening (E\&S) of nuclear fuel cycle

43 options (Wigeland, et al. 2014). A major objective of this effort was to identify fuel cycle

44 options that offer significant benefits relative to the current once-through commercial

45 nuclear fuel cycle in the U.S. with respect to nine specified high-level criteria, such as

46 waste management and resource utilization, to identify areas for investments in research

47 and development. This endeavor is a key pillar of the U.S. DOE FCT effort to enable

48 development and deployment of sustainable fuel cycles that improve performance and 
49 ensure long-term viability in significant areas such as waste management and resource

50 utilization. As part of this initiative, a wide variety of physics and inventory analyses

51 have been developed and documented for explicit nuclear fuel cycles. Using these

52 analysis examples, the physics data and performance metrics were calculated for each

53 evaluation group assuming a fully deployed and developed fleet (equilibrium state) that

54 generates a fixed amount of energy per year. These comprehensive analyses and

55 accompanying supporting documentation are assembled in a standardized catalog

56 framework (Idaho National Laboratory 2014) that enables exploration of the performance

57 of many different fuel cycles in a consistent fashion relative to specified metrics/criteria.

58 These nuclear fuel cycle studies were subject to a systematic peer review within a team of

59 collaborators at multiple national laboratories within the DOE complex. Specifically,

60 engineers and scientists at Argonne National Laboratory (ANL), Brookhaven National

61 Laboratory (BNL), Idaho National Laboratory (INL), Lawrence Livermore National

62 Laboratory (LLNL), and Oak Ridge National Laboratory (ORNL) performed and

63 reviewed the physics analyses.

64

65 One of the assumptions made during the E\&S was that the performance of fuel cycles

66 with intermediate spectrum reactor systems approaches that of fast spectrum systems and

67 therefore they were included with fast spectrum systems. The present paper aims to

68 evaluate the validity of that inclusion for the performance of intermediate spectrum

69 systems, when compared to fast spectrum systems, in one distinct fuel cycle option. In

70 addition, the paper is also motivated by the possibility that some intermediate spectrum

71 systems, in this context defined by the fission reaction spectra of the reactor system, 
72 could provide benefits similar or comparable to fast spectrum systems. Therefore,

73 intermediate spectrum systems could be an attractive implementing technology to achieve

74 the performance benefits identified in the E\&S. It should be noted that the use of a 75 particular technology does not necessarily imply an "intermediate spectrum". In this

76 study, an intermediate spectrum system was defined as a reactor system with a majority

77 (more than $50 \%$ ) of fissions occurring between $1 \mathrm{eV}$ and $10^{5} \mathrm{eV}$. The objective of this

78 paper is to compare the performance of intermediate spectrum critical reactors and fast

79 spectrum critical reactors for a specific fuel cycle with continuous recycling of $\mathrm{U} / \mathrm{Th}$ and

80 only Th fertile feed. The intermediate reactor systems include a tight lattice pressurized

81 heavy water reactor (PWR- $\mathrm{D}_{2} \mathrm{O}$ ), a tight lattice boiling light water reactor (RBWR-Th), a

82 continuously refueled molten salt reactor (MSR), and a sodium-cooled reactor with

83 hydride fuel (SFR-ThH). The reference fast spectrum system is a sodium-cooled fast

84 reactor with metal thorium fuel (Wigeland et al., 2014). The systems in this paper are

85 example configurations, which have been studied to inform on the impact of fission

86 reactions in the intermediate energy regime. These systems are intended to inform on

87 some aspects of fuel cycle performance in a technology neutral way.

\section{Physics background}

91 Thorium-based fuel cycles have been proposed for over half a century due primarily to

92 the relative abundance of thorium compared to uranium. In a continuous recycling mode,

93 thorium-fed systems exhibit the potential for breeding in thermal, intermediate, and fast

94 neutron energy space due to $\eta$ (eta), the reproduction factor (number of fission neutrons 
95 emitted per neutron absorbed), being greater than 2.0 . Therefore ${ }^{233} \mathrm{U} / \mathrm{Th}$ fueled systems

96 offer the possibility of a self-sustaining system with thermal, intermediate, or fast fission

97 reaction spectra. Specifically, the $\eta$ values for ${ }^{233} U$ are higher than those of the other

98 fissile nuclides over the majority of the intermediate energy regime. In contrast, the

99 intermediate ${ }^{239} \mathrm{Pu} \eta$ is greater than 2.0 only above $10^{4} \mathrm{eV}$ and between $1 \mathrm{eV}$ and $5 \mathrm{eV}$.

100 This is shown in Figure 1. However, for all nuclides, $\eta$ is significantly greater in the fast 101 energy range where it increases exponentially.

102

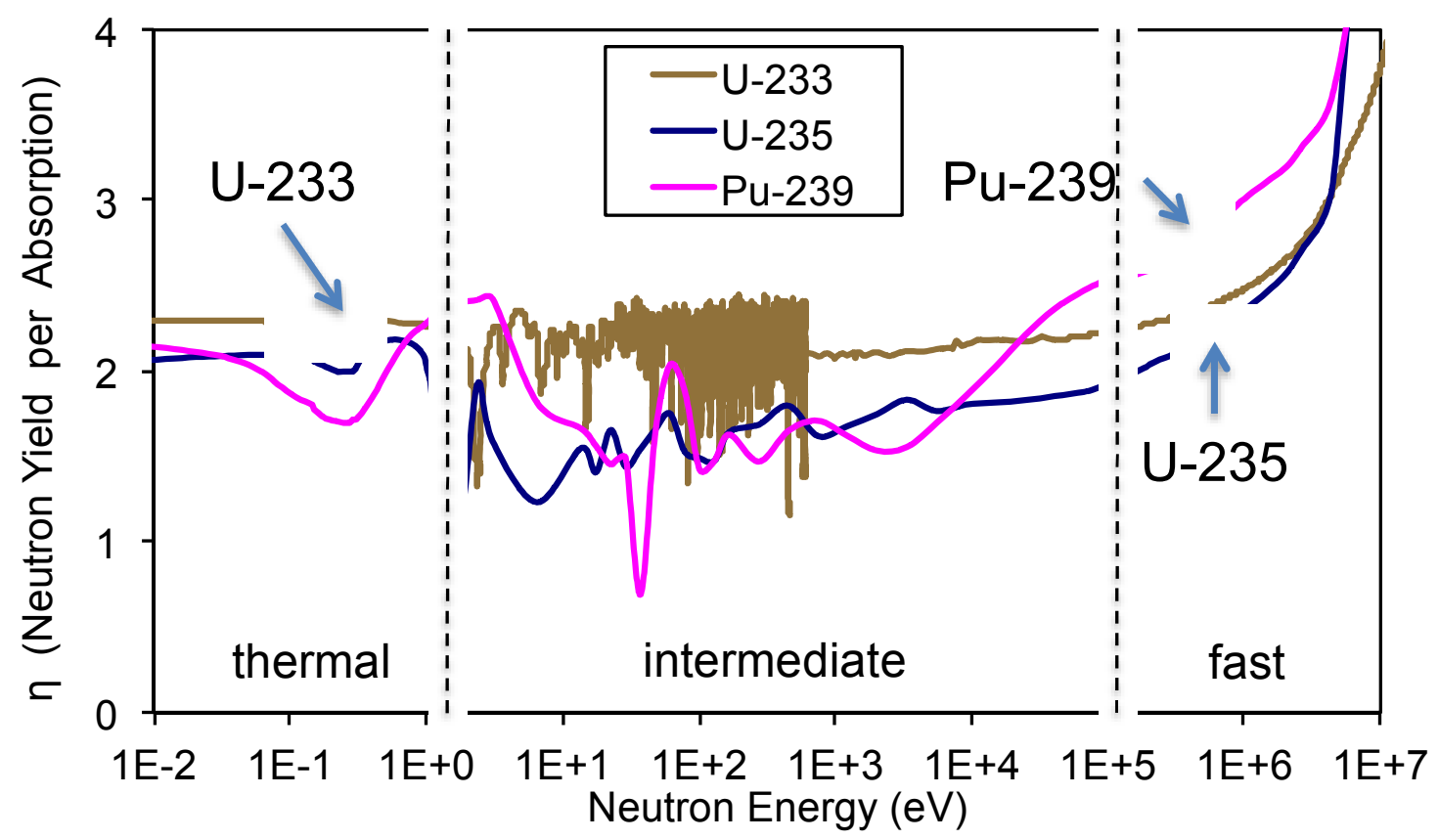

Figure 1. Neutrons produced from fission per neutron absorbed in fuel ( $\eta$ )

106 Natural thorium does not contain any fissile isotope and is a purely fertile material: the

107 likelihood of fission events is very low for neutron energies lower than $\sim 1 \mathrm{MeV}$.

108 Therefore, use of thorium fuel can be envisioned with an external source of fissile

109 material or in a fuel cycle with continuous recycle of U3 and Th. In this context, the 
110 acronym "U3" refers to the entire uranium vector produced by irradiating thorium; this

111 uranium vector contains large fractions of ${ }^{233} \mathrm{U}$ but also contains some ${ }^{232} \mathrm{U},{ }^{234} \mathrm{U},{ }^{235} \mathrm{U}$,

112 and other isotopes.

113

114 The neutron energy spectrum in a nuclear reactor is complex. It depends on the reactor

115 geometry and constituent materials (fuel, cladding, coolant, moderator, etc.), the coupled

116 conservation relationships in the system (neutron transport, heat conduction, flow field),

117 and the underlying nuclear data and constitutive properties. Condensing this highly

118 complex behavior with a continuum of neutron energies spanning many orders of

119 magnitude into a few spectral groups necessitates significant qualitative engineering

120 judgment to define the quantitative boundaries. Wigeland et al. (2014) defines the two

121 main classes, which are termed "thermal" and "fast", based on the predominant energy of

122 the neutrons causing fission in the system. Figure 2 shows the typical flux spectra of

123 thermal and fast systems along with a system with an "intermediate" spectrum that lies

124 between the two. While quite similar to the thermal neutron spectrum, the typical

125 intermediate neutron spectrum is missing the peak in the thermal neutron energy range.

126 The definitions of thermal, intermediate, and fast energy ranges assume group boundaries

127 at $1 \mathrm{eV}$ and $10^{5} \mathrm{eV}$. In this paper (as in the broader E\&S study) "thermal",

128 "intermediate", and "fast" systems are defined based on the energy range in which the

129 majority $(>50 \%)$ of the fissions occur.

130 


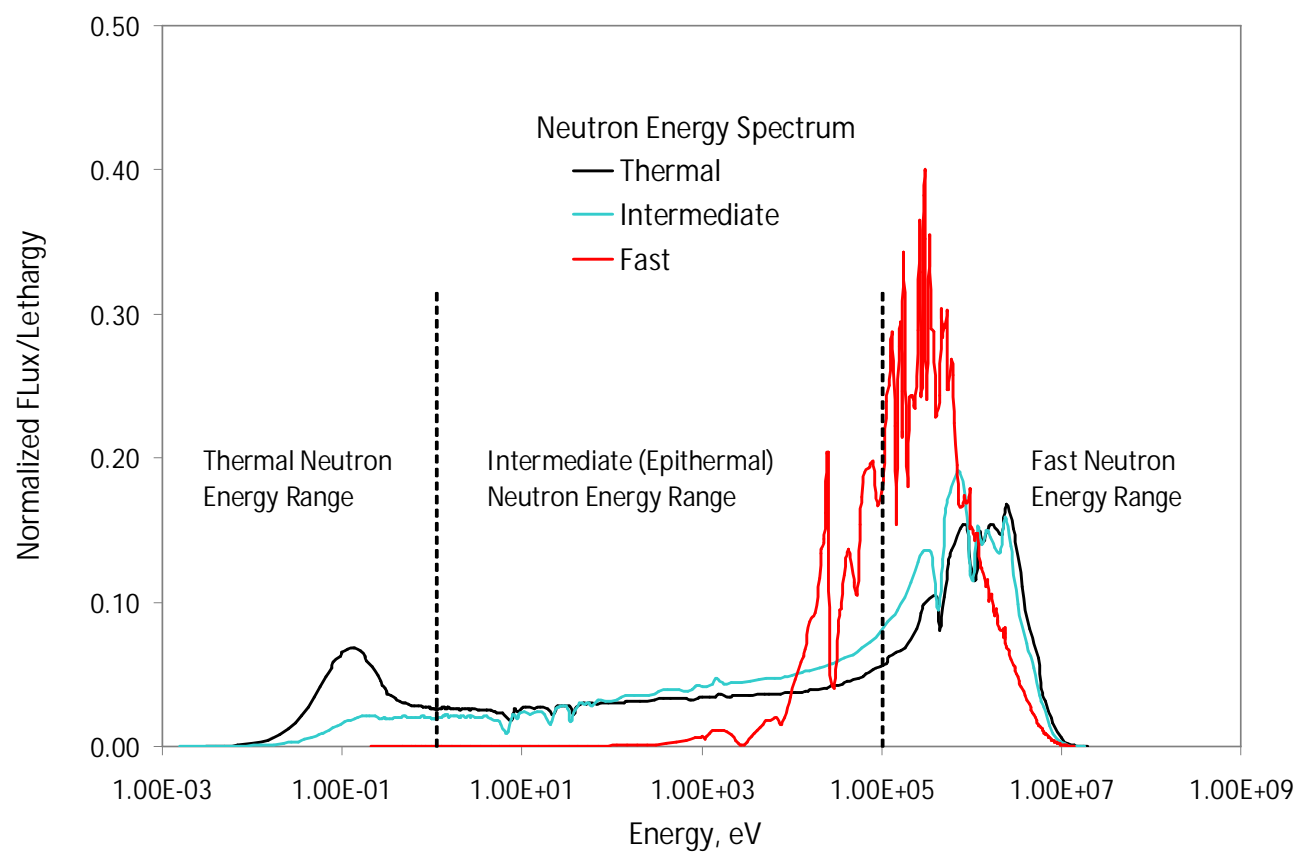

135 The fuel cycle of interest is a single-stage self-sustaining system with fertile ${ }^{232}$ Th natural

136 resource feed and continuous recycle of recovered uranium (U3, representing the entire

137 recovered uranium vector). No other fissile material is utilized within the stage, no

138 uranium natural resource is used, and no uranium enrichment is required. Several fuel

139 forms were considered in the study including oxide fuel, hydride fuel, and molten salt

140 fuel for the intermediate spectrum reactors and metallic fuel for the fast reactor. The

141 nuclear power plant/transmutation (NPPT, or reactor) is an intermediate spectrum reactor

142 or a fast reactor. To meet the objective of continuous recycle without an external source

143 of fissile material, it is necessary to analyze a configuration that is self-sustaining based

144 on the burnup dependent U3 inventory ratio of the configuration. Another important

145 quantity is the fissile inventory ratio (FIR), which is defined as the time-dependent mass 
146 of ${ }^{233} \mathrm{U},{ }^{233} \mathrm{~Pa}$, and ${ }^{235} \mathrm{U}$ divided by the initial mass of ${ }^{233} \mathrm{U}$ and ${ }^{235} \mathrm{U}$. The role of ${ }^{233} \mathrm{~Pa}$ is

147 very important in thorium based fuel cycles as it accumulates in the fuel due to its 27 day

148 half-life. Thus, due to beta decay of ${ }^{233} \mathrm{~Pa}$ into ${ }^{233} \mathrm{U}$, the amount of ${ }^{233} \mathrm{U}$ will continue to

149 increase in the discharged fuel during the cooling period. Due to the assumptions for loss

150 rates in reprocessing $(1.0 \%)$ and fabrication $(0.2 \%)$, which were fixed boundary

151 conditions for the E\&S study (Wigeland et al., 2014), a minimum uranium inventory ratio

152 of about 1.012 is required. The material flow diagram for the analyzed system is shown

153 in Figure 3. A cooling time of 5 years before reprocessing and a fabrication time of 2

154 years were assumed for every reactor system except for the MSR.

155

\section{Fuel Feed Material}

Nuclear Fuel
Nuclear Power Plant/ Transmutation
(NPPT)

Back-end

Storage and

Disposal

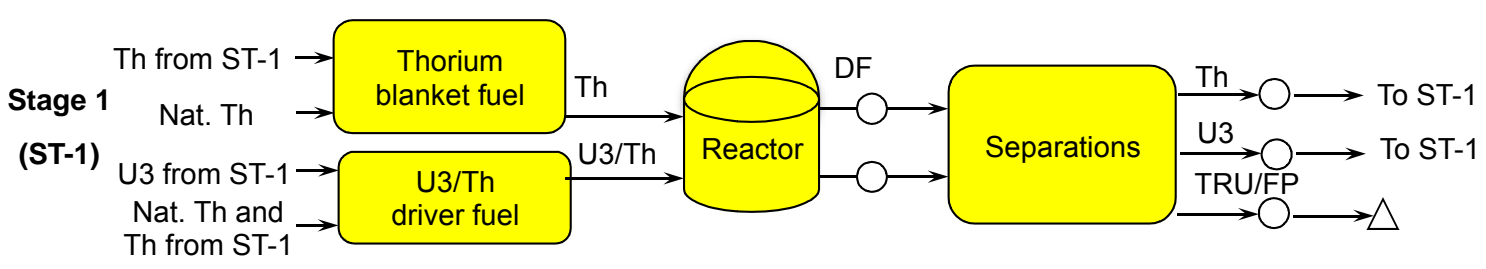

Note: Only primary material flows are shown. Material flows from imperfect separations (losses), low-level waste, and other secondary streams produced by various fuel cycle functions are not shown. Legend:

U3 $=\mathrm{U}$ recovered from Th or U3/Th $\quad \triangle=$ Nuclear Waste Disposal

$\mathrm{Th}=$ Thorium

DF = Discharged Fuel

FP $=$ Fission Products

$\mathrm{O}=$ Nuclear Material Storage

TRU = Transuranics

I = Co-separated products

Figure 3. Material flow diagram for this nuclear fuel cycle 
161 A variety of modeling approaches were utilized for the reactor physics calculations in this

162 study. All analyses used cross sections from the ENDF/B-VII.0 library (Chadwick 2006).

163 In general, a stochastic or deterministic neutron transport tool was used along with a

164 depletion solver to calculate the burnup, transmutation, and decay of isotopes in the fuel

165 cycle. The PWR- $\mathrm{D}_{2} \mathrm{O}$ and RBWR-Th configurations were studied using the Serpent tool

166 (Leppänen et al., 2014), a continuous energy Monte Carlo tool developed primarily for

167 reactor physics analysis and generation of few-group constants in complex reactor

168 geometries. Serpent has been benchmarked to a wide variety of reactor physics problems.

169 For the PWR- $\mathrm{D}_{2} \mathrm{O}$ configuration, a script was used to automatically calculate the

170 inventories after discharge and assist with cycle-by-cycle calculations to approach

171 equilibrium conditions.

173 The molten salt cooled configurations were analyzed using SCALE/TRITON from the

174 SCALE 6.1 package (Oak Ridge National Laboratory, 2011) with a cross-section library

175 based on ENDF/B-VII.0. This required development of detailed calculation methodology

176 and scripting to analyze the online feed and removal of materials at element-dependent

177 rates; additional details of the methodology and calculation approach are presented in

178 Powers et al. (2014).

180 The sodium-cooled reactor configuration with hydride fuel was analyzed using the 181 MocDown tool (Seifried et al., 2013), a two-tier solver that couples MCNP (Los Alamos 182 National Laboratory 2005) with ORIGEN (Croff 1980) and automates an efficient 183 iterative search for the equilibrium composition based on a prescribed fuel cycle scheme. 
184 The MocDown tool was modified to accommodate the specific fuel cycle schemes for

185 this work. In addition, these results were verified with a simple depletion calculation with

186 MCODE (Xu et al., 2006), which also couples MCNP with ORIGEN.

188 Each analysis was performed at or near equilibrium conditions to reflect the equilibrium

189 state of the fully developed and deployed fuel cycle. The resultant charge and discharge

190 masses were normalized per unit electricity generation. The standard assumptions of 5-

191 years for spent fuel cooling and 2-years for fuel fabrication were utilized for the solid fuel

192 cases (Wigeland et al., 2014). Each of the options explored in this paper was shown to be

193 self-sustaining while accounting for losses in separations and fabrication with continuous

194 recycle of U3 and only Th feed. The mass flow data was normalized via the equation,

$$
\bar{M}_{\text {charge }}^{\text {fuel }}\left(\frac{t}{G W e \cdot y r}\right)=\frac{P_{t h}(M W)}{B U(G W d / t) P_{e l}(M W)} \cdot \frac{365.25 d}{1 y r}
$$

198 Where $\mathrm{P}_{\text {th }}$ is the reactor thermal power in megawatts $(\mathrm{MW}), \mathrm{BU}$ is the fuel average

199 discharge burnup in gigawatt-days per ton of heavy metal $(\mathrm{GWd} / \mathrm{t})$, and $\mathrm{P}_{\mathrm{el}}$ is the reactor

200 electric power in MW. Detailed mass flow data are not presented in this paper, but the

201 methodology used to analyze the data is consistent with that in Wigeland et al. (2014).

202 Further details on the MSR systems are presented in Powers et al. (2014). The 203 radioactivity, radiotoxicity, and decay heat information for each configuration in this fuel

204 cycle were calculated according to the methodology in Wigeland et al. (2014) and Stauff 205 et al. (2015). To be technologically neutral and to focus on physics differences the 206 parameters were normalized using a uniform thermal efficiency of $33 \%$. 
208 The objective of our study, as chartered by DOE, was to develop a library of information

209 about the relative performance of various nuclear fuel cycles in a technology neutral way.

210 The study informs on differences in fuel cycle performance based on fundamental

211 physics characteristics. Some fast reactor technologies have higher outlet temperatures

212 and therefore higher thermal efficiency, but that is a design dependent feature. A fast

213 reactor could also be implemented using a technology with a low thermal efficiency.

214 High thermal efficiency is possible with thermal reactors, for example high temperature

215 gas cooled reactors with graphite moderator or a molten salt cooled reactor. The objective

216 of the study was to decouple the fundamental physics characteristics from the technology

217 implementation to the extent possible. Assuming a uniform thermal efficiency enables an

218 "apples-to-apples" comparison of fuel cycle performance, whereas assuming higher

219 outlet temperature technologies for fast reactors and lower outlet temperature for thermal

220 reactors will result in a technology-driven (as opposed to physics-driven) bias towards

221 fast reactors.

222

223 Reference sodium-cooled fast spectrum system

225 The thorium-fueled sodium-cooled fast reactor (SFR-Th) system used as a reference for

226 comparing with the intermediate spectrum systems is based on the SuperPRISM reactor

227 designed by General Electric (Dubberley et al., 2000). Although the SFR-Th core is

228 fueled with metallic thorium, the SuperPRISM oxide core configuration is modified as

229 shown in Figure 4 in order to achieve a conversion ratio of $\sim 1.012$ and maintain the ${ }^{233} \mathrm{U}$ 
230 to heavy metal ratio within reason. The core is made of 192 driver assemblies and 103

231 blanket assemblies. The total core power is $1000 \mathrm{MW}_{\mathrm{t}}$ and corresponds to a specific

232 power density of $26 \mathrm{~W} / \mathrm{gHM}$. For this core, the simulations were performed using the

233 REBUS-3/DIF3D code suite (Toppel, 1983 and Derstine, 1984) using ENDF/B-VII.0

234 libraries.

235

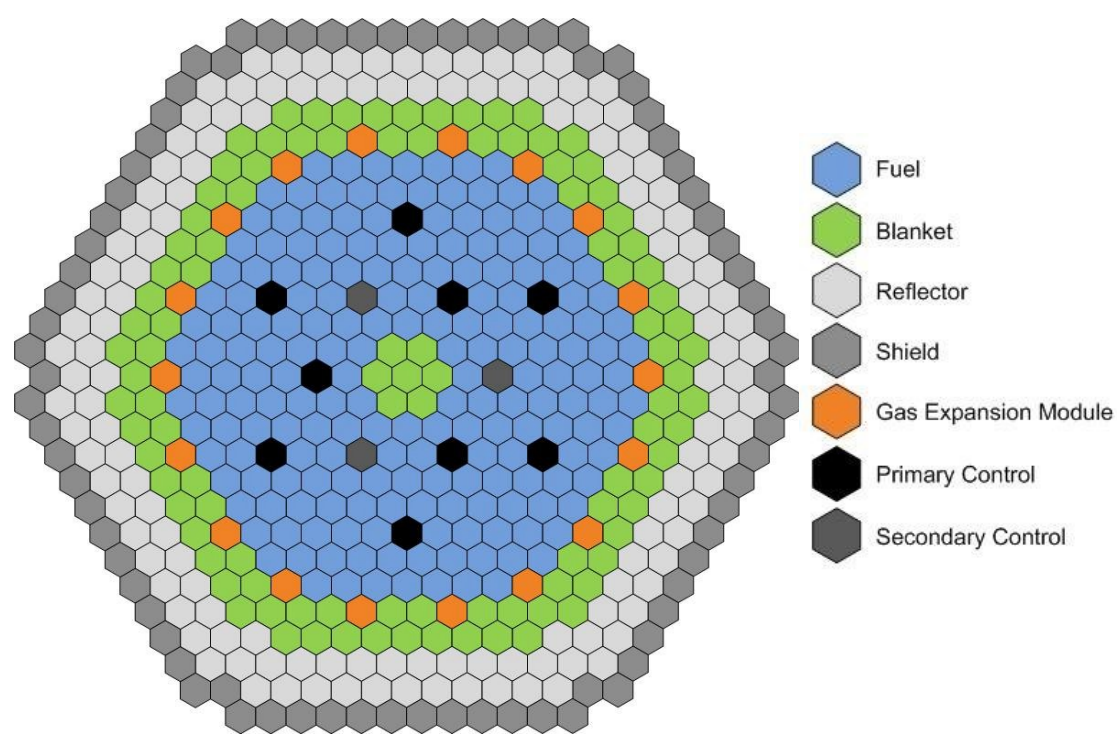

Figure 4. SFR-Th core configuration

239 Both the blanket and fuel assemblies remain in the core for three consecutive cycles and

240 are discharged with an average burnup of $1.6 \mathrm{GWd} / \mathrm{t}$ and $57.8 \mathrm{GWd} / \mathrm{t}$, respectively. At

241 equilibrium, the charged driver fuel contains approximately $18.9 \mathrm{wt} \%$ of trans-thorium

242 elements, which includes $13.9 \mathrm{wt} \%$ of ${ }^{233} \mathrm{U}$. The principal performance characteristics are

243 provided in Table 1 for the SFR-Th core. 


\begin{tabular}{|l|r|}
\hline \multicolumn{1}{|c|}{ Characteristic } & Value \\
\hline Thermal power, MWt & 1000 \\
\hline Cycle length, EFPD & 310.3 \\
\hline Number of batches & 3 \\
\hline Fuel inventory, tHM & 38.5 \\
\hline \multicolumn{1}{|c|}{ - driver } & 25.6 \\
\hline \multicolumn{1}{|c|}{ blanket } & 12.9 \\
\hline Charge fuel mass per batch, $\mathrm{t}$ & 12.8 \\
\hline Average discharge burnup, GWd/t & 24.2 \\
\hline \multicolumn{1}{|c|}{ - driver } & 57.8 \\
\hline - blanket & 1.6 \\
\hline Peak power density, $\mathrm{W} / \mathrm{cm}^{3}$ & 359 \\
\hline
\end{tabular}

\section{Analysis of water-cooled configurations}

252 The question of a water-cooled reactor with self-sustaining U3/Th fuel has been explored 253 in a number of studies, including the Light Water Breeder Reactor (Freeman et al., 1989), 254 various light water moderated parametric reactor physics studies (Permana et al., 2007;

255 Permana et al. 2008; Shwageraus et al., 2008; Yun et al., 2010; Lindley et al., 2014), 256 reduced moderation boiling water reactors (Ganda et al., 2012; Shaposhnik et al., 2013;

257 Lindley et al., 2014), and heavy water cooled pressurized water reactors (Takaki and 258 Mardiansah, 2012), among many other studies. It is outside the scope of this paper to 259 provide a comprehensive literature review or to develop such a reactor system. However 260 this, and other previous work have helped to motivate the present study. It is noted that 261 the designs in the literature are not subject to the specific approach and constraints 262 applied in the present study, which constitutes an independent and technology neutral 263 assessment of theoretical fuel cycle performance. The examples explored in the present 
264 paper are all breakeven fuel cycles (when accounting for 1.0\% losses in separations and

$2650.2 \%$ losses in fabrication), with $>50 \%$ fission reactions initiated by neutrons with

266 energies between $1 \mathrm{eV}$ to $10^{5} \mathrm{eV}$. Additional constraints on the example systems are

267 presented in the E\&S report (Wigeland et al., 2014).

268

269 It is important to note that the trade-off between breeding and criticality is a key 270 challenge in the development of a self-sustaining U3/Th water reactor with an

271 intermediate neutron energy spectrum. In this paper, two water-cooled heterogeneous

$272{ }^{232} \mathrm{Th} /{ }^{233} \mathrm{U}$ seed and blanket assembly configurations are analyzed: (1) an example $\mathrm{D}_{2} \mathrm{O}-$

273 cooled tight lattice pitch PWR (PWR- $\left.\mathrm{D}_{2} \mathrm{O}\right)$ with some conceptual similarities to systems

274 proposed by Hibi et al. (2001) and Takaki et al. (2012) and (2) an example Reduced

275 moderation Boiling Water Reactor-Thorium (RBWR-Th) similar to that proposed by

276 Ganda et al. (2012) and Shaposhnik et al. (2013). This system is similar to the Hitachi

277 RBWR concept (Takeda et al., 2007).

278

279 Heavy water cooled PWR configuration

280

281 The PWR- $\mathrm{D}_{2} \mathrm{O}$ is a heavy water-cooled PWR with similarities to designs from 282 Mitsubishi/JAERI (Hibi et al., 2001) and the University of Tokyo (Takaki and 283 Mardiansah, 2012). On a conceptual level the Mitsubishi/JAERI design was taken as an 284 example with a discharge burnup of $40 \mathrm{GWd} / \mathrm{t}$. However, the example configuration 285 analyzed in the present work is not directly representative of either the Hibi, et al. (2001) 286 or Takaki and Mardiansah (2012) designs. The active core height assumed in these 
287 calculations is $200 \mathrm{~cm}$. A radial slice of the analyzed geometry is shown in Figure 5.

288 Reflective boundary conditions were applied to all the radial surfaces while vacuum

289 boundary conditions were applied to the axial surfaces. Scoping calculations via

290 SERPENT indicated that the system is self-sustaining.

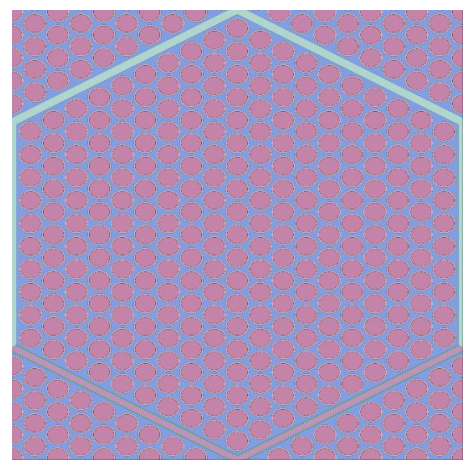

295 The PWR-D $2 \mathrm{O}$ example meets the definition of an intermediate spectrum reactor, with 296 roughly $75 \%$ of the fissions occurring between $1 \mathrm{eV}$ and $10^{5} \mathrm{eV}$. The isotopic 297 convergence of the recovered uranium vector after multiple recycling calculations is 298 shown in Figure 6. The radially reflected multiplication factor at near-equilibrium is 299 shown in Figure 7. 


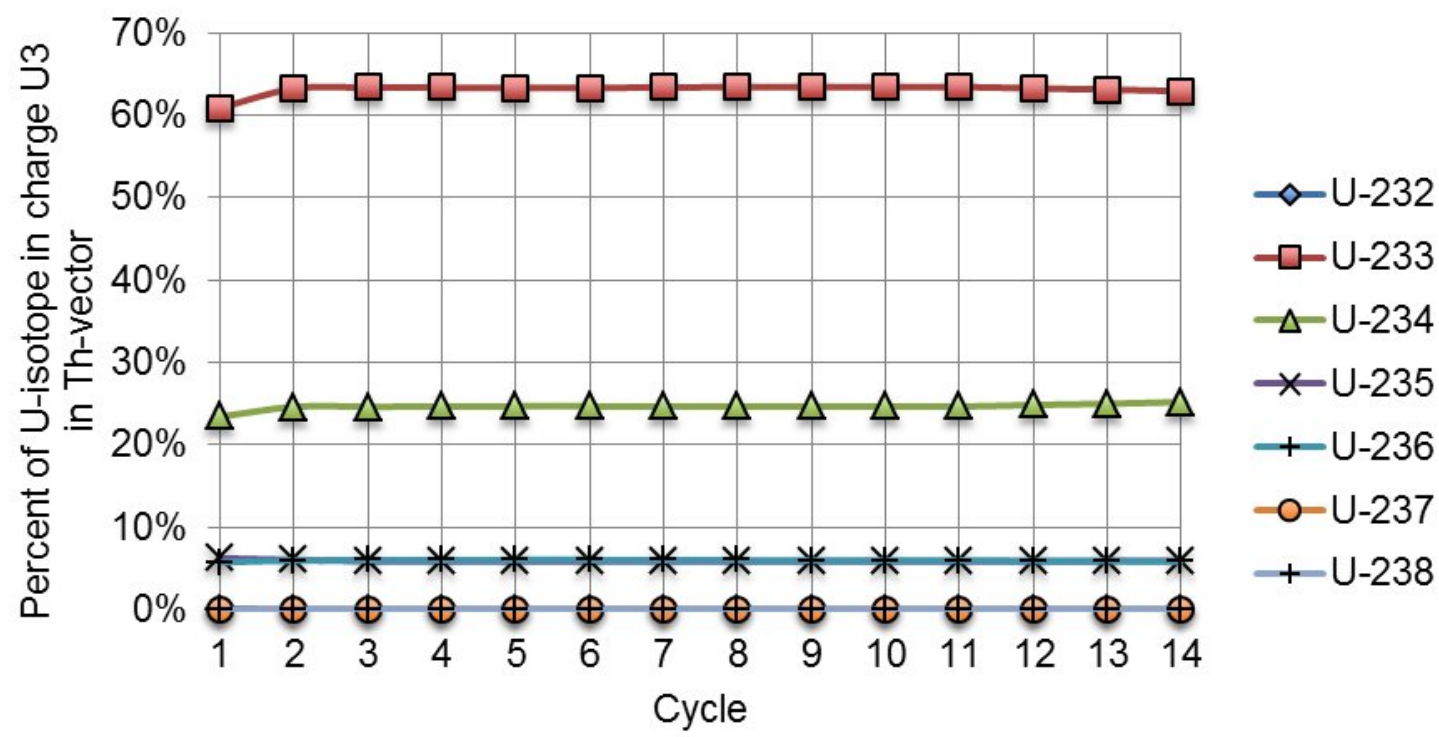

303 Figure 6. Convergence of $\mathbf{U} 3$ isotopic vector as a function of recycle for $\mathrm{D}_{\mathbf{2}} \mathrm{O}$-cooled PWR

304

305

306

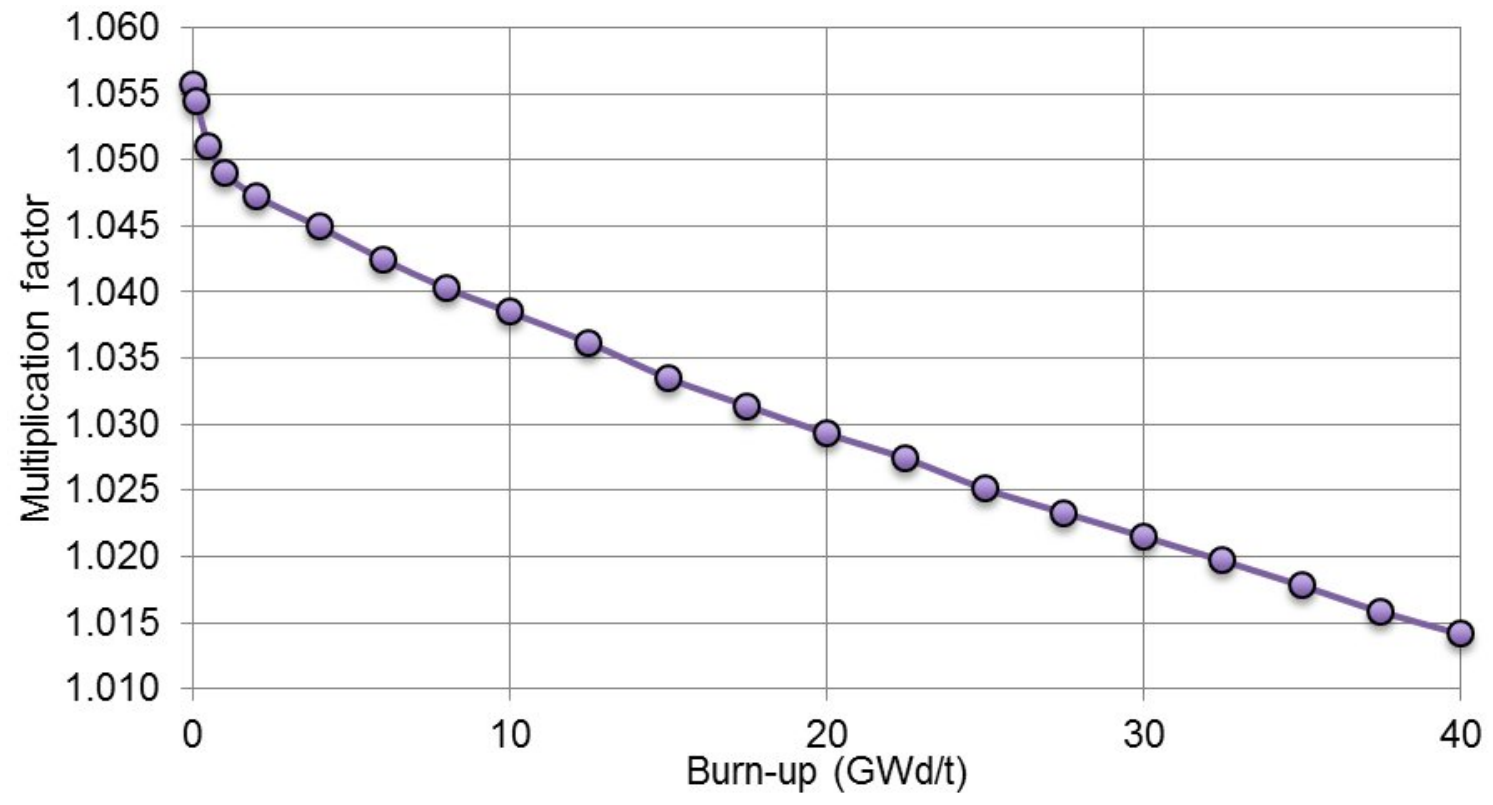

Figure 7. Radially reflected multiplication factor for $\mathrm{D}_{2} \mathrm{O}$-Cooled $\mathrm{PWR}$ at near equilibrium 
310 The equilibrium cycle mass flows in the fuel cycle were generated assuming 5 years for

311 cooling and 2 years for fabrication. A $40 \mathrm{GWd} / \mathrm{t}$ discharge burnup was targeted with

312 assumptions of a 3-batch fuel management scheme and a radial leakage and absorption in

313 reflectors/core structures of $2.5 \%$ of reactivity. The uranium inventory ratio at a near

314 equilibrium condition, after accounting for losses and decay, is $\sim 1.01$. Therefore, the

315 system is a very slight breeder at near equilibrium, but is reasonably close to self-

316 sustaining. The assumed reactor parameters are shown in Table 2 and fuel parameters in

317 Table 3.

319 It is noted that the assumed fuel management scheme and leakage fraction will have an

320 impact on achievable burnup. Potential sensitivities related to the number of fuel batches

321 and neutron leakage were explored in Brown and Todosow (2015) for similar systems

322 with U/Th fuel. With a few design modifications, a higher fuel burnup could be achieved.

323 For example, if the number of fuel batches were increased to 5 and the radial leakage and

324 absorption in reflectors/core structures were on the order of $0.8 \%$ (representative of a

325 large "pancake" core), then the discharge burnup of the configuration can reach 74

$326 \mathrm{GWd} / \mathrm{t}$.

327

328

Table 2. Reactor Parameters for $\mathrm{D}_{2} \mathrm{O}$-Cooled PWR

\begin{tabular}{|l|l|}
\hline Parameter & Stage Number \\
\hline Stage & 1 \\
\hline Core Configuration & Tight pitch hex \\
\hline Core Thermal Power, MWt & $1200^{*}$ \\
\hline Net Thermal Efficiency, \% & 33 \\
\hline
\end{tabular}

$329 *$ Value is assumed based on 313 assemblies with an assembly power of $3.84 \mathrm{MWt}$ 
Table 3. Fuel Parameters for $\mathrm{D}_{2} \mathrm{O}$-Cooled PWR

\begin{tabular}{|c|c|c|c|}
\hline \multicolumn{2}{|l|}{ Parameter } & \multicolumn{2}{|l|}{ Fuel Type } \\
\hline \multicolumn{2}{|l|}{ Purpose } & $\begin{array}{l}\text { Driver } \\
\text { (Th) }\end{array}$ & $\begin{array}{l}\text { Blanket } \\
\text { (Th) }\end{array}$ \\
\hline \multicolumn{2}{|c|}{ Chemical Form } & Oxide & Oxide \\
\hline \multicolumn{2}{|c|}{ Physical Form } & $\begin{array}{l}\text { Pin } \\
\text { Bundle - } \\
\text { Ductless }\end{array}$ & $\begin{array}{l}\text { Pin } \\
\text { Bundle } \\
\text { Ductless }\end{array}$ \\
\hline \multicolumn{2}{|c|}{$\begin{array}{l}\text { Average Discharge } \quad \text { Burnup, } \\
\mathrm{GWd} / \mathrm{t}\end{array}$} & 45.1 & 2.2 \\
\hline \multirow{4}{*}{$\begin{array}{l}\text { Fuel } \\
\text { Composition }\end{array}$} & $\begin{array}{l}\text { Initial Nuclear } \\
\text { Material(s) }\end{array}$ & $\mathrm{U} 3 / \mathrm{ThOX}$ & ThOX \\
\hline & $\begin{array}{l}\text { (U-235+ U- } \\
\text { 233)/Total U }\end{array}$ & $68.9 \%$ & $0.0 \%$ \\
\hline & $\begin{array}{l}\text { Th/Total heavy } \\
\text { metal }\end{array}$ & $85.9 \%$ & $100.0 \%$ \\
\hline & TRU/Total HM & $0.0 \%$ & $0.0 \%$ \\
\hline \multicolumn{2}{|c|}{$\begin{array}{l}\text { Fuel Residence Time in Reactor, } \\
\text { EFPY }\end{array}$} & 8.2 & 8.2 \\
\hline
\end{tabular}

\section{Light water cooled BWR configuration}

335 Similar versions of the RBWR-Th design from 2012 (Ganda et al., 2012) and 2014

336 (Gorman et al., 2014) were analyzed independently via Serpent and MocDown at BNL

337 and ANL, respectively. Except for the initial fuel loading, the RBWR-Th is charged with

338 only thoria $\left(\mathrm{ThO}_{2}\right)$ and sends only fission products to waste, recycling all actinides except

339 for losses that end up in the waste streams. The design is a variant of the RBWR-AC core

340 proposed by Hitachi, in which the $\mathrm{UO}_{2}$ and $\mathrm{MOX}$ fuels are arranged in a hexagonal tight-

341 lattice, has a high outlet void fraction, axially segregates seed and blanket regions, and

342 fits within an Advanced Boiling Water Reactor (ABWR) pressure vessel. The RBWR-Th 
343 shares these characteristics but replaces depleted $\mathrm{UO}_{2}$ with $\mathrm{ThO}_{2}$ as the primary fertile

344 fuel, eliminates the internal blanket while axially elongating the seed region, and

345 eliminates absorbers from the axial reflectors.

347 However, it is notable that due to the strongly negative void reactivity coefficient, the

348 RBWR-Th with pure thorium resource feed may experience issues with shutdown

349 margin; design studies are presently ongoing to resolve this issue (Zhang et al., 2013;

350 Shaposhnik et al., 2014). The radial and axial geometry of the RBWR-Th modeled by

351 BNL is shown in Figure 8. The FIR and radially-reflected multiplication factors

352 calculated for this example system are shown in Figure 9. Table 4 and Table 5 describe

353 the RBWR-Th core parameters and pin geometry used in the ANL MocDown model.

354 Table 6 shows the physics parameters and incident fission neutron spectrum calculated by

355 ANL and BNL for the two similar RBWR-Th configurations. Note the agreement in the

356 energy distribution of the incident neutrons, which shows that the two examples meet the

357 intermediate spectrum definition ( $\sim 70 \%$ of fissions in the $1 \mathrm{eV}$ to $100 \mathrm{keV}$ range). There

358 is a significant difference between the two example systems analyzed here. The example

359 analyzed at ANL is similar to a recent iteration of the RBWR-Th design (Gorman et al.

360 2014) and is expected to have adequate shutdown margin with control blades. However,

361 the example analyzed at BNL is similar to an earlier iteration of the design (Ganda et al.,

362 2012) and would require innovative approaches, such as those suggested by Shaposhnik

363 et al. (2014), to meet shutdown margin constraints. Shutdown margin is the key driver in

364 the difference in the two example systems and also in the achievable discharge burnup. 
365 The objective of presenting these results is to illustrate the impact of important design

366 considerations on potential fuel cycle parameters.

367

368

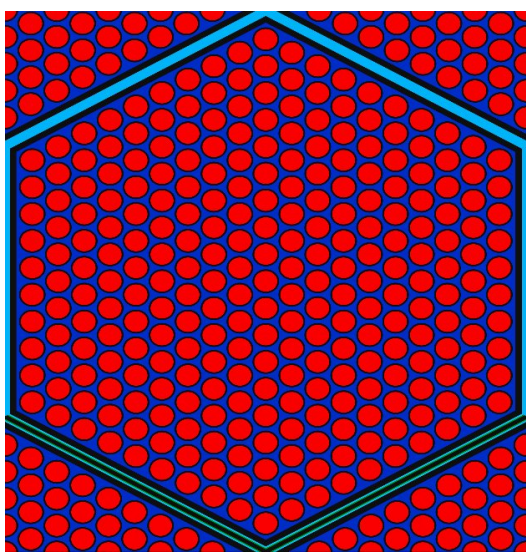

(a)

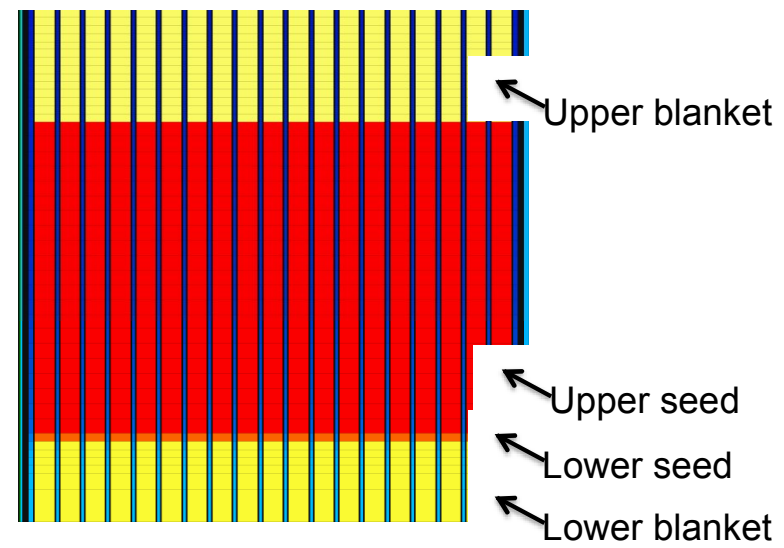

(b)

Figure 8. Radial (a) and axial (b) slice of RBWR-Th assembly

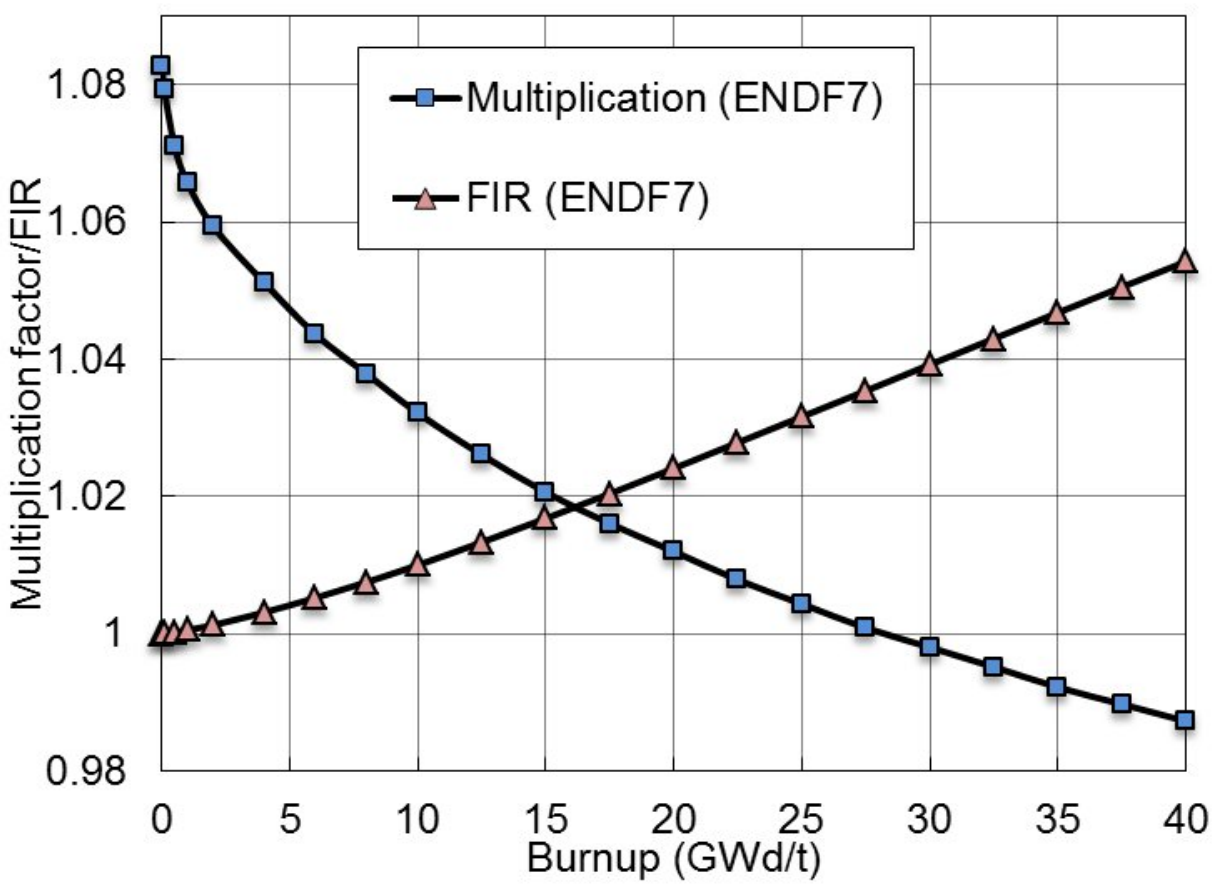

Figure 9. Radially reflected multiplication factor for RBWR 


\begin{tabular}{|l|c|}
\hline Thermal power, MWt & 3926 \\
Core mass, tHM & 361 \\
Fuel residence time, EFPD & 2300 \\
Number of batches & 5 \\
Cycle length, EFPD & 460 \\
Average discharge burnup, GWd/t & 23.3 \\
Pin power, MWt & 0.0188 \\
Primary coolant pressure, $\mathrm{MPa}$ & 7.25 \\
Coolant inlet temperature, ${ }^{\circ} \mathrm{C}$ & 282.56 \\
Exit quality & 0.277 \\
\hline
\end{tabular}

Table 5 RBWR-Th seed and blanket pin geometry (Gorman et al., 2014)

\begin{tabular}{|l|c|}
\hline Axial height (blanket/seed/blanket), $\mathrm{cm}$ & $40 / 300 / 40$ \\
Cladding inner diameter, cm & 0.885 \\
Cladding outer diameter, cm & 1.005 \\
Pin pitch, cm & 1.135 \\
Fuel smear density, g/cm ${ }^{3}$ & 8.99 \\
Heavy metal smear density, gHM/cm & 7.90 \\
Fuel cross section temperature, K & 900 \\
Structure cross section temperature, K & 600 \\
\hline
\end{tabular}

Table 6 Calculated RBWR-Th physics parameters

\begin{tabular}{|l|cc|}
\hline Case & ANL & BNL \\
\hline Fissions in E $<1 \mathrm{eV}$ range, (at MOL) & $8 \%$ & $4 \%$ \\
Fissions in 1 eV $-100 \mathrm{keV}$ range, (at MOL) & $70 \%$ & $70 \%$ \\
Fissions in $100 \mathrm{keV}<\mathrm{E}$ range, (at MOL) & $22 \%$ & $26 \%$ \\
\hline Core Avg. Discharge Burnup $\left(\mathrm{B}_{\mathrm{d}}\right)[\mathrm{GWd} / \mathrm{t}]$ & 23.3 & 40.0 \\
\hline Fissile Inventory Ratio* & 1.00 & 1.05 \\
\hline
\end{tabular}

\section{Homogeneous molten salt cooled configurations}

385 A relevant alternative technology is a MSR system. The analysis approach consisted in

386 starting with a thermal-spectrum MSR configuration and decreasing the moderator 
387 content until an intermediate spectrum was obtained. This can be thought of as

388 approaching an intermediate spectrum by reducing moderation in a thermal-spectrum

389 design as opposed to adding moderator to a fast-spectrum design.

391 MSR analysis requires modeling several material feed and removal functions: direct

392 discard of fuel salt, salt treatment (passive) processes, separations (active) processes that

393 extract species such as rare earth element fission products, and fresh feed of thorium.

394 These processes are applied sequentially in this work in the following order: (1) salt

395 discard, (2) uranium and protactinium separations, (3) salt treatment and separations, and

396 (4) thorium addition.

398 Salt treatment and separations calculations were performed using effective cycle times

399 from the Molten Salt Breeder Reactor (MSBR) program and batch removal calculations,

400 as detailed in Powers et al. (2014). The MSBR program defined a cycle time as the

401 amount of time required to remove $100 \%$ of a given element from a fuel salt. Cycle times

402 were converted to removal fractions for this work, with a removal fraction of 1.0 used

403 when the depletion time step length matched or exceeded the cycle time for an element.

405 The methods used to model MSR material flows in this work approximate continuous

406 flow processes as a series of batch processing steps due to limitations in the current

407 depletion codes. While this batch processing approximation introduces some level of

408 error, short depletion steps minimize the magnitude of the errors introduced. Based on the

409 results of a study described in Powers et al. (2014) that examined the net effect that

410 depletion step length had on modeling material flow processes and depletion, 3-day 
411 depletion steps were used for all MSR calculations unless otherwise noted in order to

412 allow $100 \%$ removal of protactinium during a single depletion step.

414 Sensitivity to the ${ }^{233} \mathrm{U}$ radiative capture cross section evaluation is an issue that was 415 recently identified in the literature for molten salt reactors (Aufiero et al., 2013). This

416 issue is especially relevant for intermediate spectrum MSR systems. This sensitivity is

417 reviewed here, because it significantly impacts the neutron economy in these systems and

418 also because the ENDF-BVII.0 cross section evaluation used in the present paper yields

419 higher radiative capture rates in ${ }^{233} \mathrm{U}$ than the JEFF-3.1 evaluation used in many recent 420 studies (Aufiero et al., 2013). The differences in this cross section between several 421 standard evaluations are shown in Figure 10.

423 The ${ }^{233} \mathrm{U}$ cross section in ENDF/VII.0 has new evaluations in the fast energy region and 424 resonance region (Chadwick et al., 2006). In the fast energy range, the capture cross 425 section was renormalized using the available experimental data. The primary neutron 426 capture data in the range $(10 \mathrm{keV}-0.5 \mathrm{MeV})$ are some sparse legacy data from Hopkins 427 and Diven (1962). The ENDF/VII.0 evaluation in this energy range shows significantly 428 improved agreement with legacy measurements. There is additional legacy measured 429 capture cross section data in this energy regime (Spivak et al., 1957), which shows good 430 agreement with the data in Hopkins and Diven (1962). The ENDF/B-VII.0 evaluation 431 shows improved agreement, when compared to ENDF/B-VI.8 or JEFF-3.1, with the 432 available measured neutron capture cross section data in the energy range ( $10 \mathrm{keV}-0.5$ $433 \mathrm{MeV}$ ). It should be noted that the JEFF-3.1 ${ }^{233} \mathrm{U}$ evaluation is based on JENDL 3.3 and 
434 ENDF/B-VI.4. The data from Hopkins and Diven (1962) and Spivak et al. (1957) are

435 legacy data. Cross section measurement, data reduction, and uncertainty quantification

436 techniques have matured considerably since these legacy measurements were made.

437 Additionally, the data are sparse over orders of magnitude in energy. It is noteworthy that

438 JEFF-3.2 has adopted the ENDF/B-VII evaluation. However, there is still a lack of recent

439 experimental data over a very large energy space.

441 It is noted that the performance of the MSR systems in the present work was calculated

442 using ENDF/B-VII.0 evaluations. Therefore, the calculated radiative capture in ${ }^{233} \mathrm{U}$ will

443 be higher than studies that utilize other cross section sets, and in particular studies that

444 rely on JEFF cross sections, such as Aufiero et al. (2013).

445

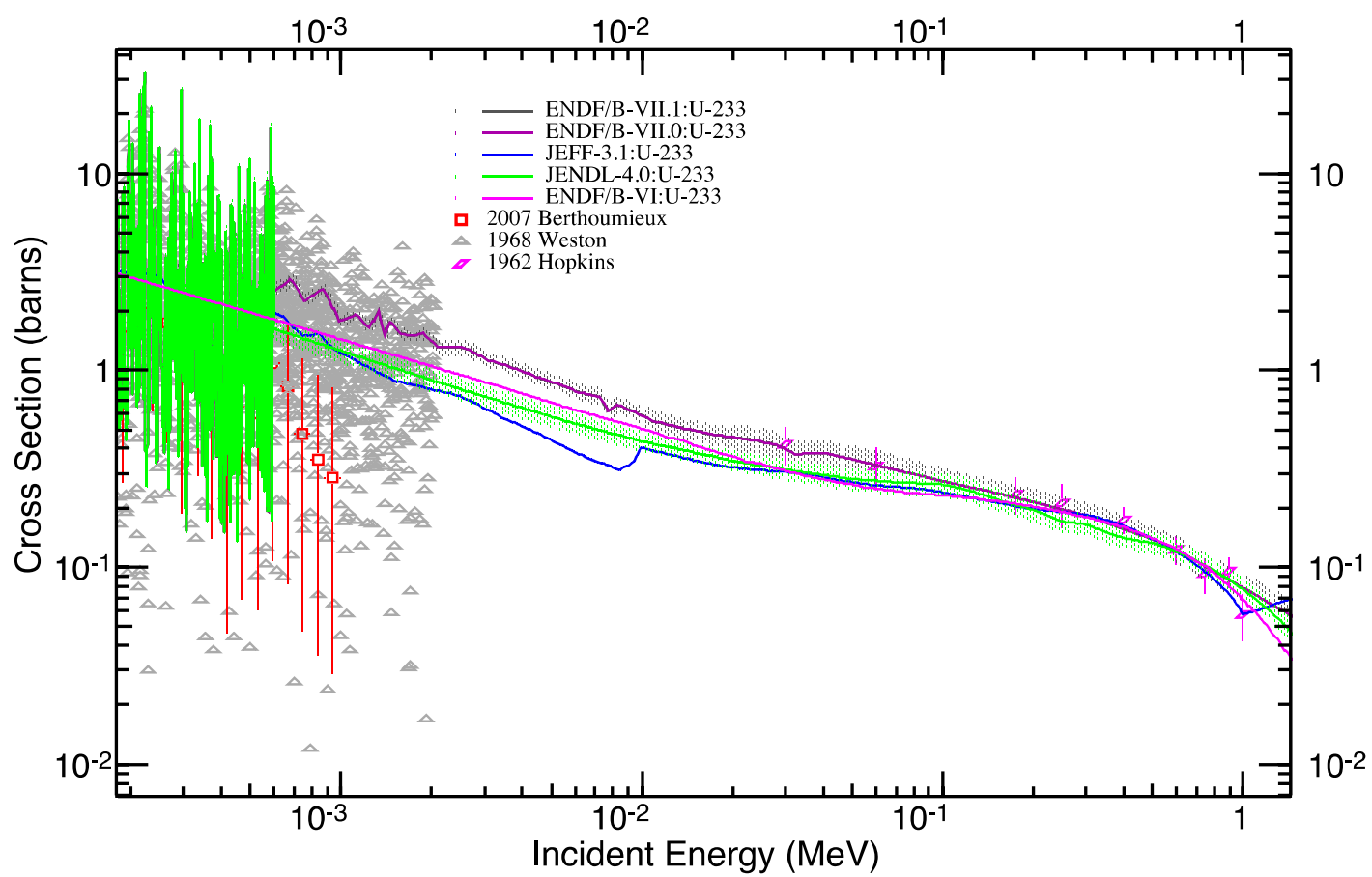

Figure 10. ${ }^{233} \mathrm{U}$ radiative capture cross section and measurements 
450 The unit cell from the MSR design used for a thermal MSR system provided a starting 451 point (Powers et al., 2014). The central fuel salt flow channel in this unit cell was then 452 expanded, increasing the relative volume fraction of the unit cell occupied by fuel salt 453 and decreasing the moderator to fuel ratio, thereby hardening the neutron spectrum. 454 Figure 11 provides an illustrative example of this process by showing the MSBR Zone I 455 cell design (13 vol\% fuel salt) and the MSBR Zone II cell design (37 vol\% fuel salt), as 456 described in Bettis and Robertson (1970), and an effective unit cell with a flow channel 457 containing the volume-weighted average ( $\sim 20 \mathrm{vol} \%)$ of the two zones.

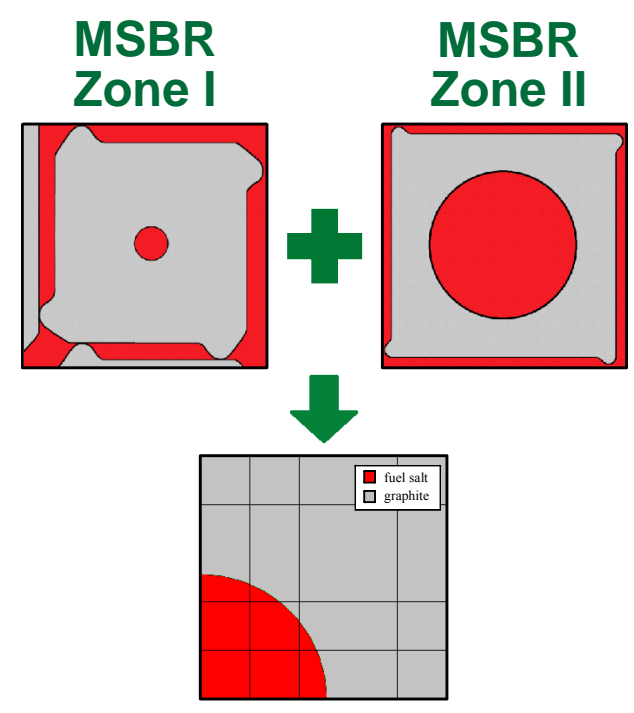

460 Figure 11. MSBR Zone I and Zone II designs and a core volume-weighted Effective Unit

463 Parametric analyses were performed varying the fuel salt volume fraction to identify an 464 example intermediate-spectrum MSR system that could also maintain self-sustaining 465 criticality at equilibrium. The calculations used to identify the example system assume a 
466 specific fuel salt (FLiBe) and fission product extraction rate, with additional details

467 provided in Powers et al. (2014). The lattice geometry is variable. These results are not

468 intended to provide universal insight on the reactor physics feasibility of MSR concepts.

469 The results are example configurations that are representative of specific possible 470 approaches to an MSR system. The results were achieved by hardening the spectrum in a

471 thermal MSR design with the goal of increasing the fraction of fission events in the 472 intermediate energy range.

474 Figure 12 shows the fraction of fissions occurring in the intermediate energy region, 475 which varies almost linearly with the fuel salt volume fraction in the MSR unit cell. 476 These results indicate that a fuel salt volume fraction of just below $37 \%$ would be the 477 minimum to ensure over $50 \%$ intermediate fissions. Figure 13 informs on the feasibility 478 of these unit cell designs by showing the equilibrium infinite multiplication factor as a 479 function of fuel salt volume fraction in the MSR unit cell; an equilibrium infinite 480 multiplication factor of over 1.02 is required to account for neutron leakage. Design 481 improvements and optimizations could provide small increases to the multiplication 482 factors shown in Figure 13, so all of the unit cell designs in the range of $13 \%$ to $42 \%$ fuel 483 salt volume fraction may be feasible, but additional calculations would be needed to 484 explicitly support these engineering judgments. Fuel salt volume fractions above $42 \%$ 485 would become difficult to design for critical operation for this specific set of lattice and 486 salt configurations, though the range could perhaps be extended to $45-50 \%$ in this system 487 with some effort. Changing the salt from $\mathrm{FLiBe}\left(2 \mathrm{LiF}+\mathrm{BeF}_{2}\right)$ salt to another carrier salt 488 (e.g., LiF or chloride salts) could also prove beneficial but would need to be investigated, 

as these alternate carrier salts would push the system into the fast spectrum at large fuel

490 salt volume fractions. These salts have been considered for various fast MSR concepts

491 since the 1950s (Briant and Weinberg 1957; Forsberg 2007).

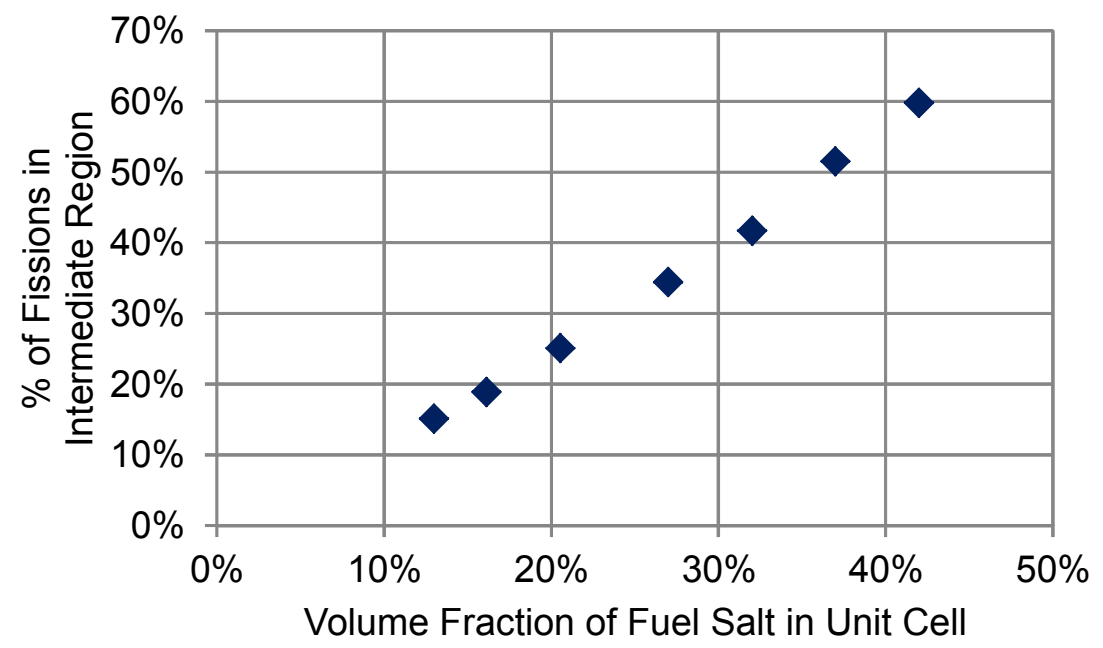

493 Figure 12. Percentage of fissions caused by neutrons in the intermediate energy region as a 494 function of volume fraction of fuel salt in an MSR unit cell 495

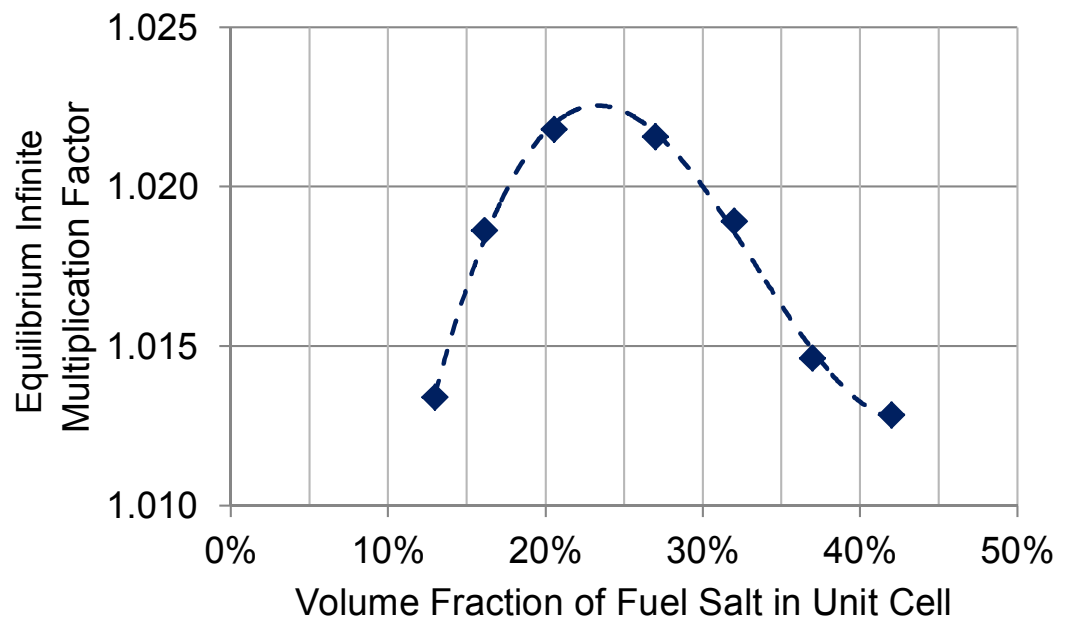

497 Figure 13. Equilibrium infinite multiplication factor as a function of volume fraction of fuel 498 salt in an MSR unit cell 
500 Based upon the results shown in Figure 12 and Figure 13, two unit cells appear to be of

501 particular interest: one with $37 \mathrm{vol} \%$ fuel salt that produces $51 \%$ intermediate fissions

502 and one with $42 \mathrm{vol} \%$ fuel salt that produces $60 \%$ intermediate fissions. It is worth noting

503 that the $37 \mathrm{vol} \%$ fuel salt unit cell happens to be the same as in the MSBR Zone II unit

504 cell, which was intentionally designed to have a harder neutron energy spectrum to

505 increase the breeding ratio in that core region. Depletion studies indicate that both unit

506 cell designs require about the same thorium feed material flow rate, so their resource

507 utilization should be fairly similar.

508

509 Sodium-cooled reactor with UThH fuel configuration

510

511 There is ongoing work at the University of California at Berkeley to develop a sodium-

512 cooled reactor technology that continuously recycles U3 using a hydride fuel form

513 (Zhang and Greenspan 2014). In this paper, the design is referred to as the sodium-

514 cooled fast reactor with hydride fuel, or the SFR-ThH. However, it is notable that the

515 fission reaction spectrum is actually intermediate under the definition used in this study.

516 A major benefit of this configuration is the ability to achieve a negligible sodium void

517 worth for a relatively large SFR core ( $\sim 3000 \mathrm{MWt})$. Specifically, using U3 instead of

518 TRU as the main fissile material greatly reduces the void coefficient of reactivity due to

$519{ }^{233} \mathrm{U}$ 's more gradual increase in the reproduction factor, $\eta$, upon spectrum hardening. In

520 addition, using hydride fuel to moderate the neutrons softens the spectrum so that most of

521 the fission reactions occur in the intermediate spectrum in which the $\eta$ slope is more 522 gradual. 
524 The design parameters, pin geometry, and material compositions are shown in Table 7

525 and Table 8, respectively. The charge fuel composition was obtained after performing 526 multiple recycle calculations via MocDown until equilibrium was reached. This 527 composition was then used as input in a radially reflected pin model to calculate the 528 discharge burnup (no cooling or reprocessing losses assumed) and the corresponding U3

529 inventory ratio. A depletion calculation was performed to produce the radially-reflected 530 multiplication factor versus burnup curve shown in Figure 14. Assuming $0.5 \%$ radial 531 leakage, which is within the stated $0.5-1 \%$ (Zhang and Greenspan 2014) and a 5-batch 532 refueling scheme, the achievable discharge burnup is $40 \mathrm{GWd} / \mathrm{t}$ according to the linear 533 reactivity model (Driscoll et al., 1990). The percent of fissions between $1 \mathrm{eV}$ and $10^{5} \mathrm{eV}$ 534 is $66 \%$, indicating that this reactor design is representative of an intermediate spectrum 535 based on the definition in the study. The uranium and transuranic inventory ratio of the 536 design was 1.0 accounting for $0.1 \%$ fabrication losses and decay. The standard loss rates 537 in Wigeland et al. (2014) were not used, but with a small adjustment in U3 in Th fraction 538 or hydrogen to heavy metal ratio these losses could be accounted for and the physics 539 performance would be very similar. 


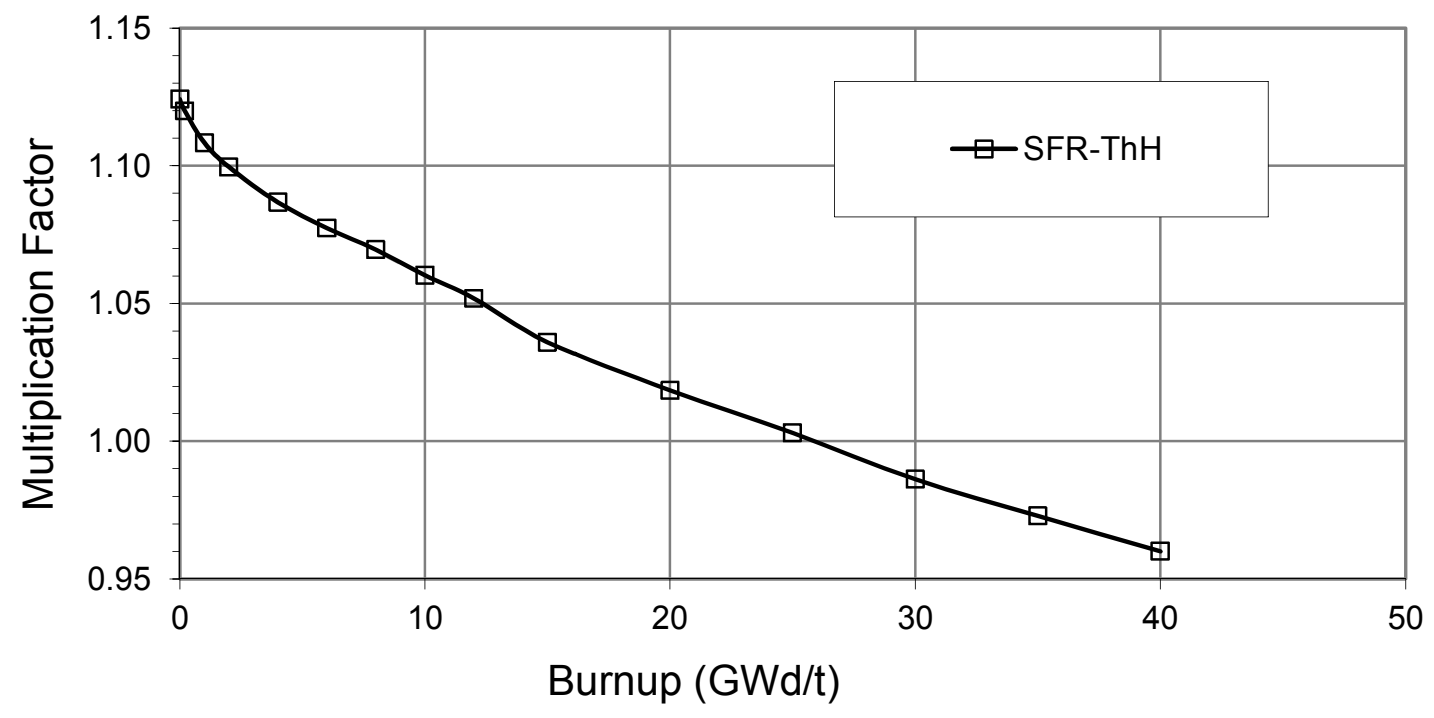

Table 7. SFR-ThH core design parameters

\begin{tabular}{|l|l|}
\hline Parameter & Value \\
\hline Thermal power, MWt & 3000 \\
\hline Core mass, tHM & 109 \\
\hline Fuel residence time, EFPD & 1450 \\
\hline Number of batches & 5 \\
\hline Cycle length, EFPD & 290 \\
\hline $\begin{array}{l}\text { Average discharge burnup } \\
\text { GWd/t }\end{array}$ & 40 \\
\hline Pin power, MWt & 0.0093 \\
\hline Coolant density, g/cm3 & 0.851 \\
\hline
\end{tabular}

\begin{tabular}{|l|l|}
\hline Dimension & Value \\
\hline
\end{tabular}




\begin{tabular}{|l|l|}
$\begin{array}{l}\text { Axial height (blanket/seed/blanket) } \\
\mathrm{cm}\end{array}$ & $60 / 80 / 60$ \\
\hline Cladding inner diameter, cm & 0.6324 \\
\hline Cladding outer diameter, cm & 0.744 \\
\hline Pin pitch, cm & 0.82584 \\
\hline Fuel pellet smear density, g/cm ${ }^{3}$ & 8.55 \\
\hline Heavy metal smear density, gHM/cm & 3.53 \\
\hline Fuel stoichiometry & $\mathrm{UThH}_{0.5}$ \\
\hline Blanket stoichiometry & $\mathrm{ThH}_{0.5}$ \\
\hline
\end{tabular}

\section{Comparison of analyses for different reactor representations}

552 The different intermediate spectrum designs using Th-based fuel investigated in this

553 study were selected to represent a diverse sampling of this unique design space. These

554 options came from recent literature or were designed specifically for this study with 555 many approximations and a limited number of constraints. These designs use different

556 fuel forms, coolants, and moderators to achieve the continuous recycling of U3/Th while

557 fitting the definition of intermediate spectrum. The fraction of fissions in each energy 558 range is shown in Figure 15 for each of these four designs. 


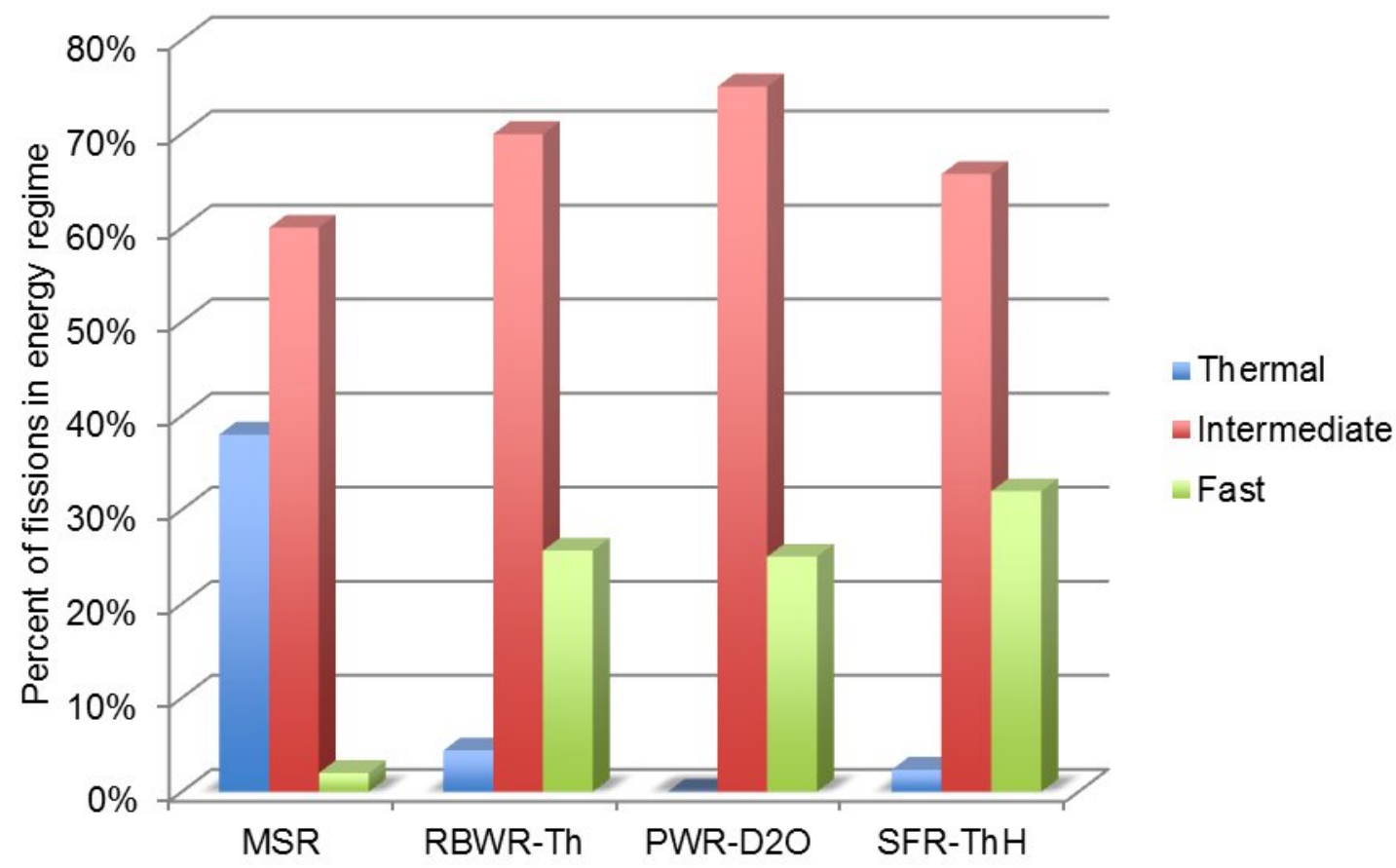

561 Figure 15. Percent of fissions in thermal, intermediate, and fast energies for several reactor systems

564 The flux and fission reaction spectra are shown in Figure 16 and Figure 17, respectively 565 for the PWR-D 2 O, RBWR-Th, MSR, and SFR-ThH. The values were plotted over the 566 same set of equal-lethargy 238 energy bins. The main observation from Figure 15 is that 567 the three solid fuel designs have significant amounts of fast fissions and little to no 568 thermal fissions, while the MSR has almost $40 \%$ of its fissions caused by thermal

569 neutrons. This reflects how an intermediate spectrum design can be achieved by 570 hardening the spectrum of a thermal reactor (as in the MSR) or softening the spectrum of 571 a fast reactor (as in SFR-ThH). 
574 These observations yield the following conclusions about the intermediate systems

575 analyzed in this study. The solid fuelled systems tend to be "high intermediate" systems,

576 meaning that although the intermediate spectrum drives the fission events, the systems

577 also exhibit a significant percent of fast fissions. In contrast, the liquid fueled systems

578 tend to be "low intermediate" systems, because although the majority of fissions occur in

579 the intermediate energy range the systems also exhibit a significant percent of thermal

580 fissions. This conclusion is limited to the example systems analyzed in this particular

581 study. The case with the highest percent of intermediate fissions, the PWR- $\mathrm{D}_{2} \mathrm{O}(75 \%)$,

582 also has the lowest percent of thermal fissions $(0.3 \%)$. However, all cases with more than

$58350 \%$ intermediate fissions are representative of an intermediate spectrum technology

584 realization, in the context of this study.

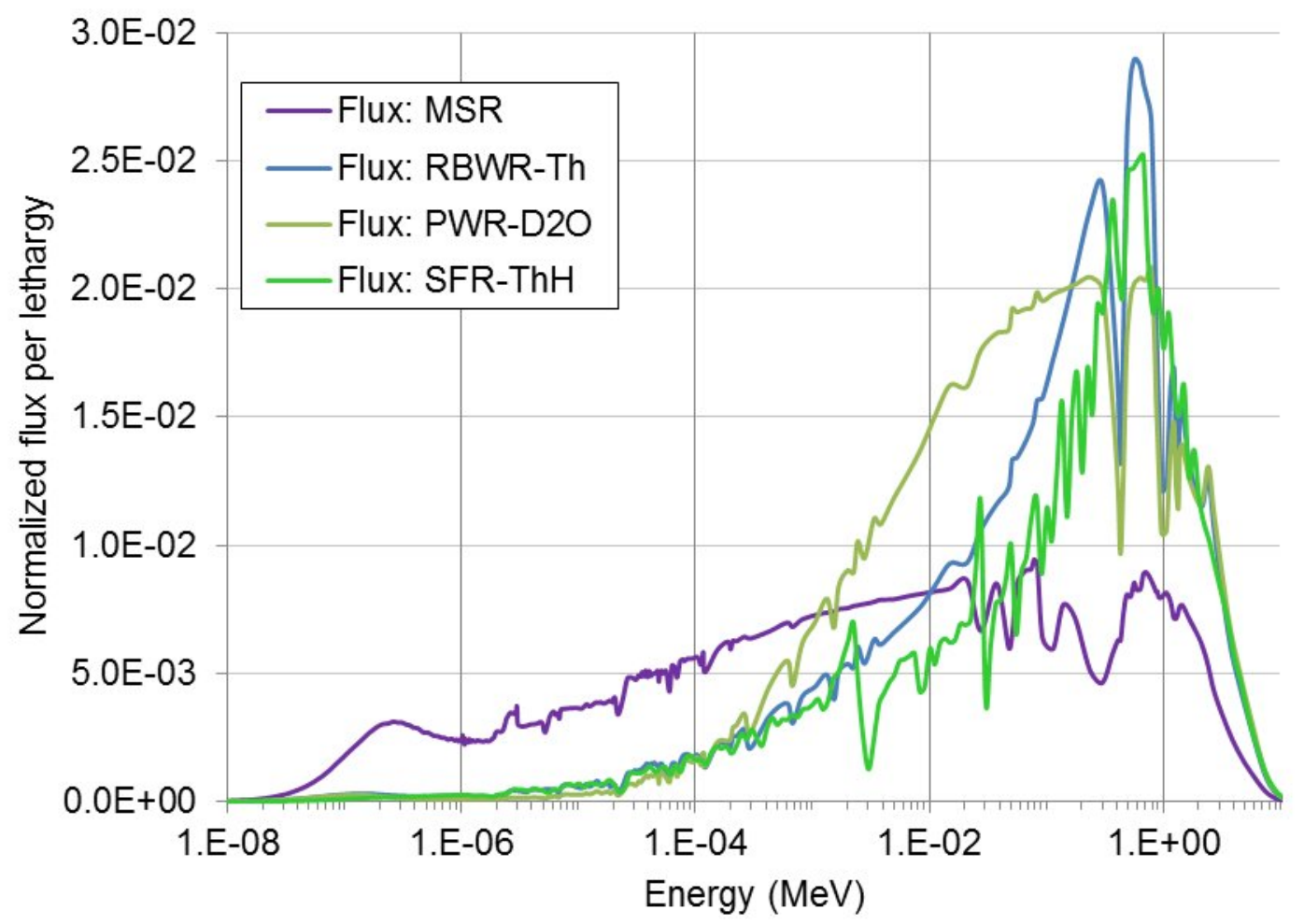




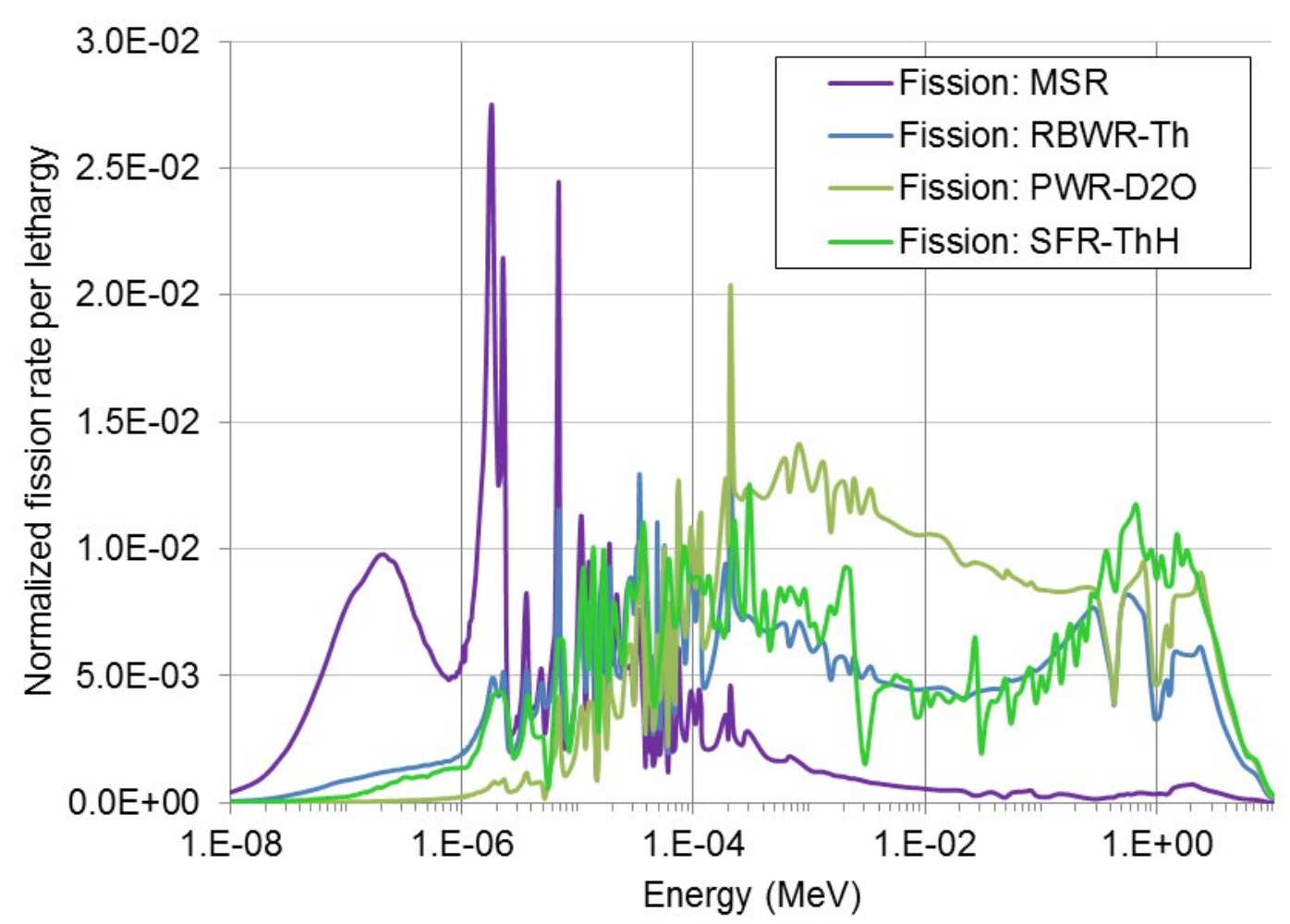

Figure 17. Fission reaction spectra comparison for intermediate spectrum systems

592 Other than the MSR case, which used graphite moderator, relatively light moderators are

593 utilized in these example configurations. However, it is noted that in spite of the

594 difference in moderator mass, a fission reaction spectrum similar to that of the MSR can

595 be obtained with a hydrogen moderator. This assertion is justified by considering a

596 system that does not quite meet the definition of intermediate spectrum in this study: a

597 PWR with light water moderator in a breakeven U3/Th fuel cycle. 
599 Scoping calculations were performed regarding a PWR configuration with the objective

600 of achieving a self-sustaining system with continuous recycle of recovered uranium in

601 thorium and only fertile thorium resource feed. The objectives were to determine

602 whether the system was self-sustaining and whether it can be considered an intermediate

603 spectrum system. This PWR is a heterogeneous ${ }^{232} \mathrm{Th} /{ }^{233} \mathrm{U}$ assembly that fits within the

604 form factor of a 17 x 17 Westinghouse PWR assembly (Yun et al., 2010). This geometry

605 is shown in Figure 18. Some noted caveats include the fact that the blanket fuel rods are

606 in direct contact, which would leave no room for conventional grid spacers and may lead

607 to closed thermal hydraulic channels. Additionally there is no fissile content in the

608 blanket fuel rods, which means that initially almost all of the fission events will occur in

609 the driver rods at zero burnup, the specific power is significantly de-rated versus a

610 standard PWR due to the high heavy metal loading and power generated in the seed, and

611 the thermal hydraulic feasibility of the configuration has not been studied and may

612 present concerns for viability.

613

614

615

616

617

618

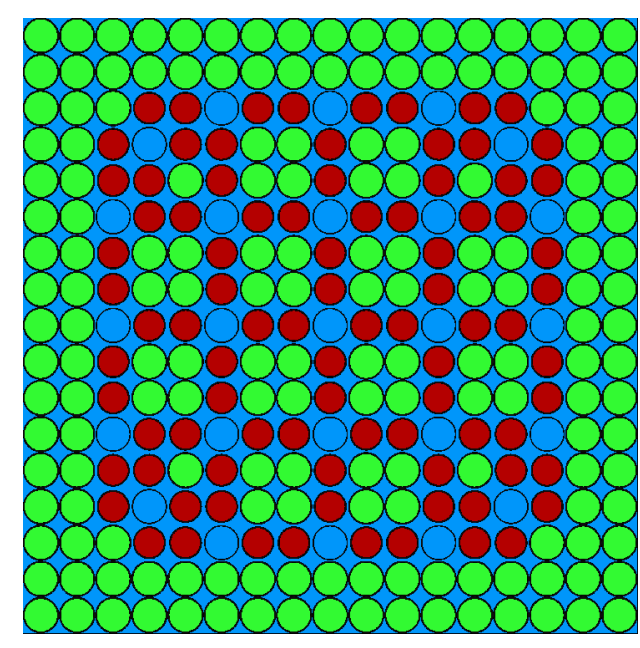

Figure 18. PWR assembly configuration analyzed (seed rods are red, blanket rods are green) 
619 The key questions regarding this light water cooled PWR include: (1) Is the

620 configuration self-sustaining with a degraded uranium vector at equilibrium? (2) Is this

621 PWR a thermal spectrum or an intermediate spectrum reactor technology? It is noted that

622 none of these questions was answered definitively in previous studies.

623

624 A study was performed to assess the sensitivity of this configuration to several fissile

625 fractions of a degraded U3 vector. The intention is to explore the criticality and the

626 sustainability. An example degraded U3 vector was assumed for these scoping

627 comparisons. The vector is shown in Table 9. The vector was used with the assembly

628 model shown in Figure 18 with several driver zone U3 fractions. The percent of U3 in

629 Th was assumed to be $8.8 \%, 12.8 \%$, and $14.5 \%$ respectively. The cases straddle the

630 transition from critical to subcritical and also from self-sustaining to a system requiring

631 an external resource feed. The infinite multiplication factor and total uranium inventory

632 ratio are shown in Figure 19 and Figure 20, respectively. It is evident that the $12.8 \%$ U3

633 case is the closest to the required inventory ratio and criticality constraints, although the

634 uranium vector is continuing to degrade and the system is not in an equilibrium state.

635 Consequently, this $12.8 \%$ configuration will be further detailed. It is noted that the

636 optimized fissile content of this system at equilibrium would be different.

637

638 Table 9. U3-vector utilized for degraded vector sensitivity studies

\begin{tabular}{|l|l|}
\hline Isotope & Mass percent in $U$ \\
\hline${ }^{232} \mathrm{U}$ & $0.05 \%$ \\
\hline${ }^{233} \mathrm{U}$ & $63.03 \%$ \\
\hline${ }^{234} \mathrm{U}$ & $25.12 \%$ \\
\hline${ }^{235} \mathrm{U}$ & $5.92 \%$ \\
\hline${ }^{236} \mathrm{U}$ & $5.88 \%$ \\
\hline${ }^{237} \mathrm{U}$ & $0.00 \%$ \\
\hline${ }^{238} \mathrm{U}$ & $0.00 \%$ \\
\hline
\end{tabular}




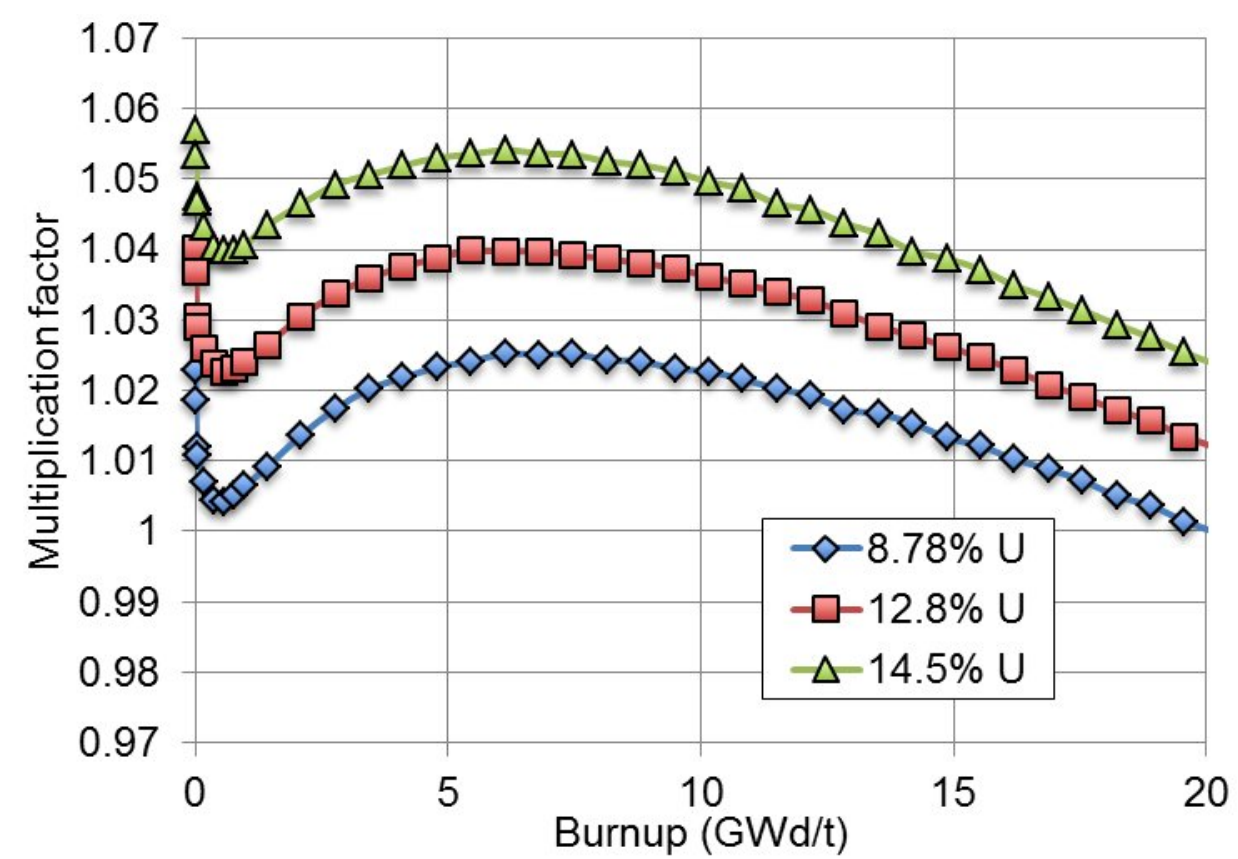

640

641

642

643

644

645

646

647

648 configuration. This answers the question regarding the spectral characteristics of this

649 configuration. The fact that a majority of fissions do not occur in any energy regime

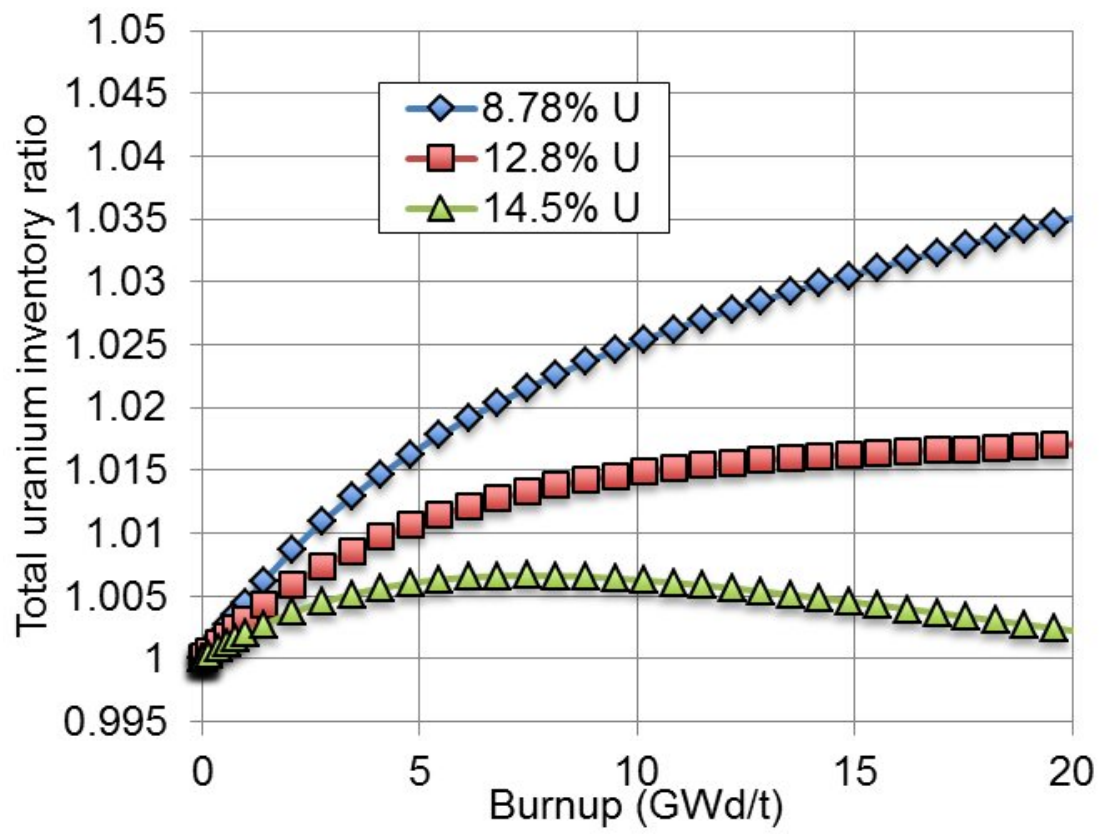

Figure 20. Total uranium inventory ratio as a function of $U 3$ content in the driver zone

The percent of fissions in each energy regime is shown in Figure 21 for the $12.8 \%$ 
650 indicates that this geometry is neither representative of a thermal spectrum or 651 intermediate spectrum, by the definition used in this study. Instead, this is a "mixed" 652 configuration with shared characteristics of both thermal and intermediate spectra.

654

660 model and a non-linear reactivity model. To calculate the cycle length and other

661 associated parameters a quadratic reactivity model was utilized. The stability of non-

662 linear reactivity models, and in particular quadratic reactivity models, has been

663 extensively studied (Parks and Lewins, 1987). Given that the reactivity trace of this

664 particular configuration is almost parabolic, the $2^{\text {nd }}$ order generalized reactivity model 665 was selected for application here (Driscoll et al., 1990). The reactivity as a function of

666 burnup and associated curve-fit are shown in Figure 22. The reactivity assumes 3\% 667 neutron leakage, which yields a discharge burnup of approximately $17 \mathrm{GWd} / \mathrm{t}$ for a three668 batch core. This discharge burnup is indicated with an arrow on the plot. 
670

671

672

673

674

675

676

677

678

679

680

681

682

683

684

685

686

687

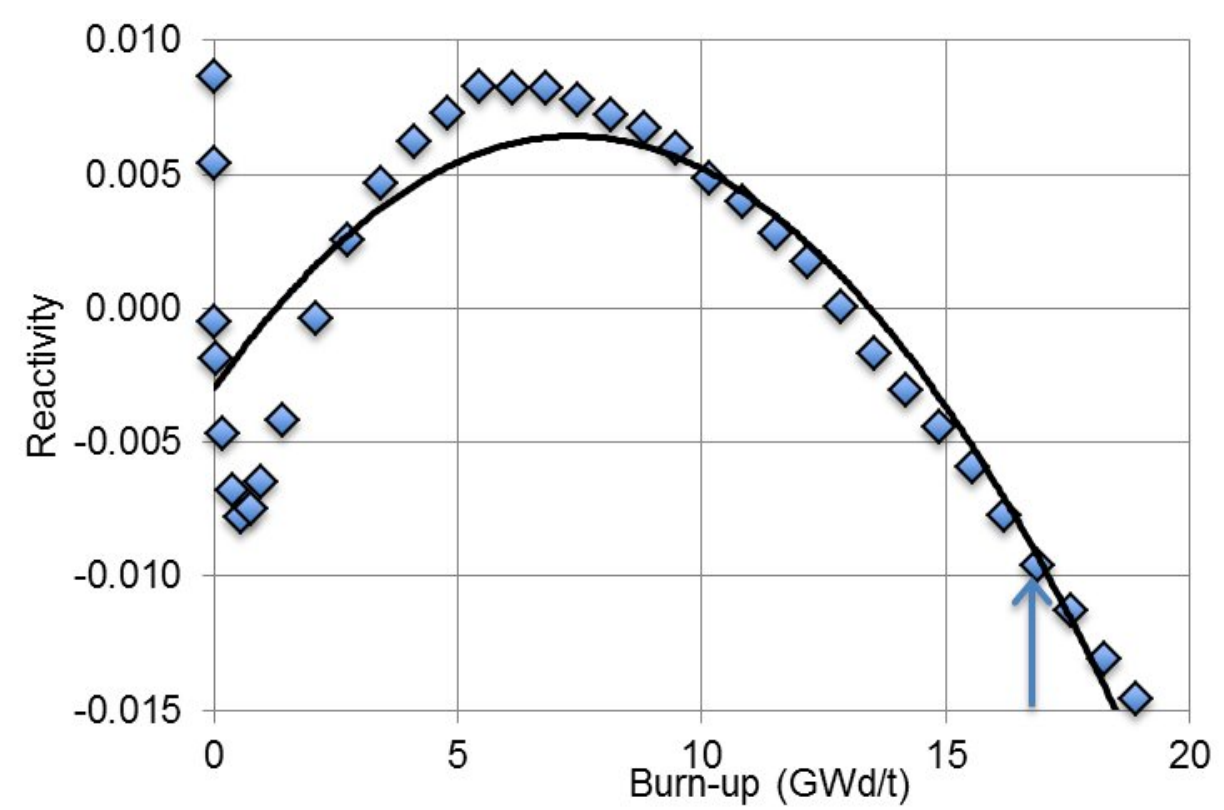

Figure 22. Reactivity as a function of burnup assuming $3 \%$ neutron leakage, a 3-batch cycle, and a quadratic reactivity model. Discharge burnup is indicated with the blue arrow.

When averaged over $17 \mathrm{GWd} / \mathrm{t}$ burnup the percent of thermal fissions is $47 \%$, intermediate fissions is $46 \%$, and fast fissions is $7 \%$. The uranium and transuranic inventory ratio, after accounting for losses and decay, is 1.010 . Therefore, this system is actually expected to be a slight breeder, although recycle to near equilibrium conditions was not performed for this case. To summarize the key findings for this realization:

- The system is neither thermal nor intermediate by the definition in this study. This should be considered a "mixed" thermal and intermediate spectrum case.

- Although the analyses indicate that the system may be self-sustaining at equilibrium, there is still uncertainty whether this is really the case. The design may not be viable and there are demonstrated issues with the ${ }^{233} U$ capture cross section in this energy regime.

- Even if self-sustaining, the system would have low burnup $(\sim 17 \mathrm{GWd} / \mathrm{t})$ and very low power density due to de-rating. 
- In addition, it was found that this PWR has a very similar fission reaction spectrum when compared to an example MSR, as shown in Figure 23. The fraction of fissions in the intermediate energy regime is $46 \%$ for the example PWR and 51\% for the example MSR. This finding supports the assertion that an intermediate spectrum design can be achieved by hardening the spectrum of a thermal reactor. In addition, it shows how two breakeven U3/Th systems can have similar fission reaction spectra even with significant differences in moderator 696

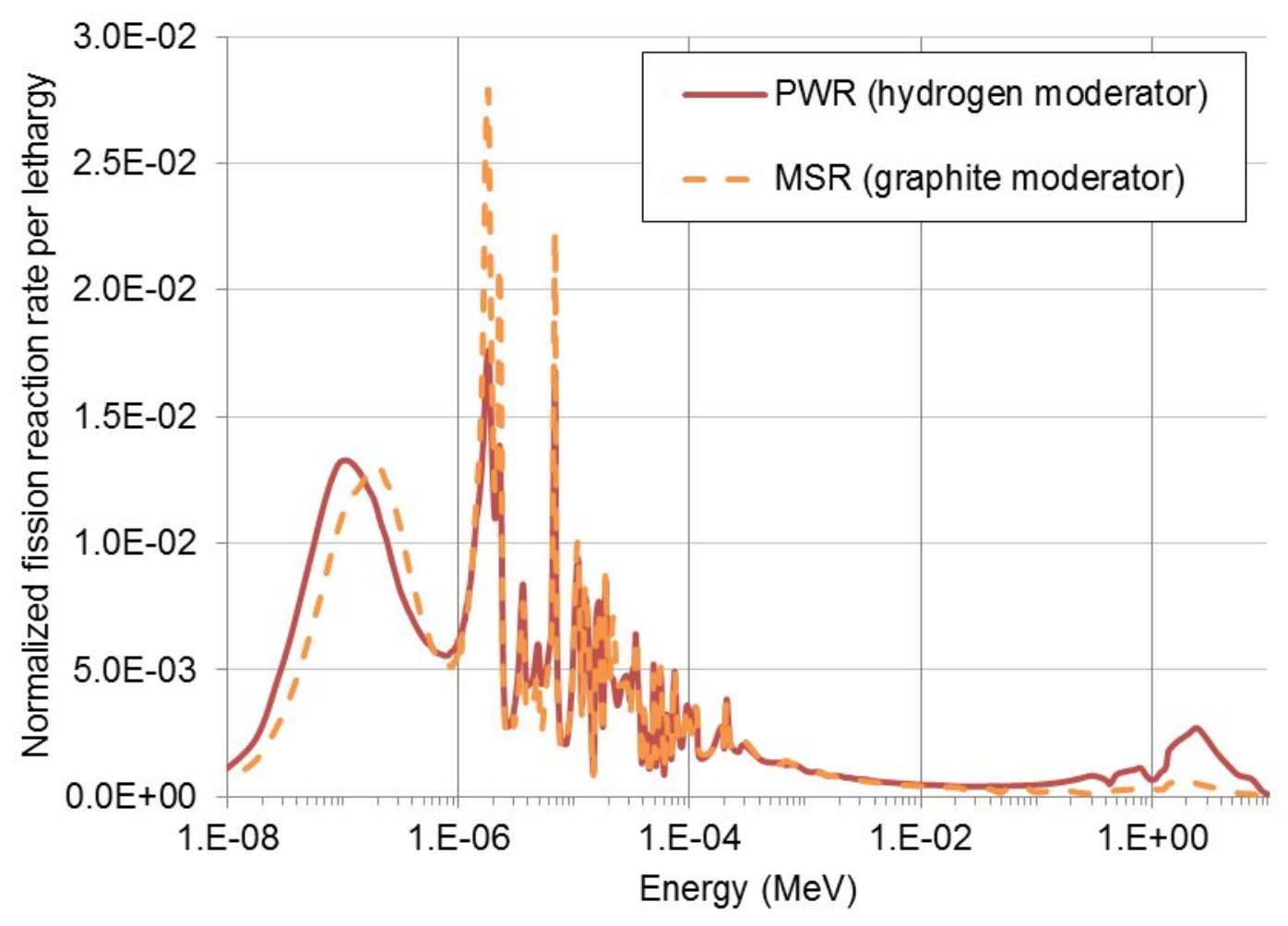

698 Figure 23. Fission reaction spectra comparison for breakeven U3/Th systems with hydrogen 
703 The over-arching goal of the effort is to compare performance of intermediate spectrum

704 systems with fast spectrum systems for this fuel cycle. In the FCT study, fuel cycles were

705 assessed with respect to high-level criteria (Wigeland et al., 2014), to inform on

706 promising options for investment in research and development. These high-level criteria

707 are associated with key quantitative metrics that are calculated based on the physics

708 analyses and mass flows developed for the analysis examples for each fuel cycle option.

709 Each criterion informs on either the benefits or challenges of the given fuel cycle option.

710 Note that only the metrics pertaining to benefit criteria (such as nuclear waste

711 management, environmental impact, resource utilizations) were calculated for the

712 intermediate spectrum designs in this study and compared to the corresponding metrics

713 values for the fast spectrum analysis example (SFR-Th). To account for uncertainties and

714 differences in calculation approaches and designs, each calculated metric is assigned a

715 letter score (A, B, C, etc.) based on a binned approach. That is, if the calculated metric

716 values for two different designs fall within the same bin range, then they exhibit the same

717 performance for that metric. More detailed descriptions of the metrics, including their

718 development, rationale, bin boundaries, and calculation methodology can be found in

719 Wigeland et al. (2014). Detailed descriptions of the metrics are presented in Appendix C

720 of the E\&S report, including parameter values and metrics calculation approaches

721 (Wigeland et al., 2014). Development of these metrics was integral to a multi-year multi-

722 laboratory study and reproduction of the metric calculation approach is outside the scope

723 of this paper. Interested readers are referred to Appendix C of the E\&S report. 
725 In this paper, three specific intermediate spectrum reactor representations, the PWR- $\mathrm{D}_{2} \mathrm{O}$,

726 RBWR-Th, and SFR-ThH, are compared to the reference fast system, an SFR with

727 metallic fuel (SFR-Th), for the benefit metrics. Comparison of the MSR system metrics is

728 not in the scope of this paper. However, MSR systems were analysis examples for several

729 options in the E\&S. Interested readers are referred to Wigeland et al. (2014) and Powers

730 et al. (2014). The mass flows at equilibrium are based on the detailed physics analyses

731 described in the paper and are normalized to the electricity generated in GWe-yr. The

732 calculated metric values and binned scores for these criteria are shown in Table 10. Key

733 acronyms used in this table include Spent Nuclear Fuel (SNF), High Level Waste

734 (HLW), Depleted Uranium (DU), Recovered Uranium (RU), Recovered Thorium (RTh),

735 and Low Level Waste (LLW).

736

737 The metrics values of the systems compared in Table 10 are all in the same bins, except 738 for the Activity of HLW at 100,000 year after discharge for the $\mathrm{D}_{2} \mathrm{O}$-cooled PWR. In

739 fact, the value of the activity for this intermediate system is right above the bin boundary

740 for this metrics $\left(23 \times 10^{-4} \mathrm{MCi} / \mathrm{GWe}-\mathrm{Yr}\right)$.

741

742 The variation in average discharge burnup, which is directly linked to the total annual

743 mass flow of fuel, is an important factor impacting the values of the environmental and

744 resource utilization metrics, the mass of HLW and the volume of LLW. The total mass

745 flow is linked through the losses to the mass of High Level Waste and to the mass of 746 natural Thorium feed required. 
748 As seen from the results, the benefit metrics performance of the analyzed intermediate

749 spectrum systems in this fuel cycle is very similar to that of the fast spectrum systems.

750 These conclusions may not be applied universally, but the examples analyzed in this

751 study represent a diverse set of technology-specific designs. It is important to note that

752 these specific intermediate spectrum designs are large cores with low neutron leakage,

753 whereas the fast spectrum example in Table 10 is a relatively small reactor core with

754 higher leakage, which consequently relies on radial breeding blankets to achieve self-

755 sustainability. Those radial blanket assemblies are typically discharged with a low

756 burnup, driving down the average discharge burnup of the SFR, which is one of the most

757 impactful parameters affecting metrics performance since it represents the amount of

758 energy released per mass of fuel. Less leaky designs (larger cores) will enable higher

759 burnup and lower mass flows per energy generated, so they will inherently score higher

760 for all metrics relating to resource utilization and waste management. So it is possible

761 that with a more optimized fast reactor design, the binned values may be improved for

762 some of the metrics. It is important to note that burnup and breeding performance of

763 intermediate spectrum systems is primarily determined by the value of $\eta$, which is highest

764 at fast energies for all fissile nuclei.

765 
767 Table 10. Comparison of performance based on several high-level criteria and associated metrics

\begin{tabular}{|c|c|c|c|c|c|}
\hline Criterion & Value and units & $\begin{array}{l}\text { SFR-Th } \\
\text { Fast } \\
\text { Spectrum }\end{array}$ & $\begin{array}{l}\text { PWR- } \mathrm{D}_{2} \mathrm{O} \\
\text { Intermed. } \\
\text { Spectrum } \\
\end{array}$ & $\begin{array}{l}\text { RBWR-Th } \\
\text { Intermed. } \\
\text { Spectrum }\end{array}$ & $\begin{array}{l}\text { SFR-ThH } \\
\text { Intermed. } \\
\text { Spectrum }\end{array}$ \\
\hline Burn-up & $\mathrm{GWd} / \mathrm{t}$ & 23.2 & 40.0 & 23.3 & 40.0 \\
\hline $\begin{array}{l}\text { Fissile } \\
\text { Inventory } \\
\text { Ratio } \\
\end{array}$ & $\begin{array}{l}\text { After } 1.0 \% \text { losses in } \\
\text { separations and } 0.2 \% \text { in } \\
\text { fabrication }\end{array}$ & 1.00 & 1.01 & 1.00 & 1.00 \\
\hline \multirow{5}{*}{ 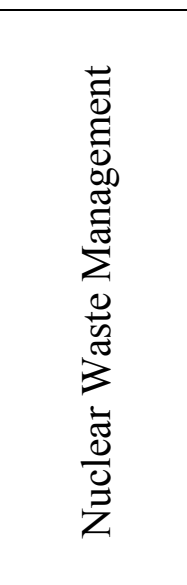 } & $\begin{array}{l}\text { Mass of SNF+HLW } \\
\text { disposed, } t / G W e-y r\end{array}$ & $1.56 / \mathrm{A}$ & $1.45 / \mathrm{A}$ & $1.45 / \mathrm{A}$ & $1.41 / \mathrm{A}$ \\
\hline & $\begin{array}{l}\text { Activity of SNF+HLW } \\
\text { (@100 years), } \\
\text { MCi/GWe-yr }\end{array}$ & $1.16 / \mathrm{C}$ & $1.43 / \mathrm{C}$ & $1.28 / \mathrm{C}$ & $1.39 / \mathrm{C}$ \\
\hline & $\begin{array}{l}\text { Activity of SNF+HLW } \\
\text { (@100,000 years),10-4 } \\
\text { MCi/GWe-Yr }\end{array}$ & $22.7 / \mathrm{C}$ & $23.5 / \mathrm{D}$ & $21.5 / \mathrm{C}$ & $12.7 / \mathrm{C}$ \\
\hline & $\begin{array}{l}\text { Mass of DU+RU+RTh } \\
\text { disposed, } t / G W e-y r\end{array}$ & 0/A & 0/A & 0/A & 0/A \\
\hline & $\begin{array}{l}\text { Volume of LLW, } \\
\mathrm{m}^{3} / \mathrm{GWe}-\mathrm{yr}\end{array}$ & 1118/D & 838/D & 1075/D & 730/D \\
\hline \multirow{4}{*}{ 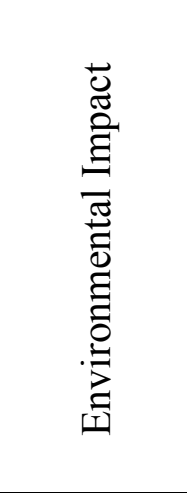 } & $\begin{array}{l}\text { Land use per energy } \\
\text { generated, } \mathrm{km}^{2} / \mathrm{GWe} \text {-yr }\end{array}$ & $0.086 / \mathrm{A}$ & $0.084 / \mathrm{A}$ & $0.084 / \mathrm{A}$ & $0.084 / \mathrm{A}$ \\
\hline & $\begin{array}{l}\text { Water use per energy } \\
\text { generated, ML/GWe-yr }\end{array}$ & 23746/B & 23728/B & 23746/B & 23728/B \\
\hline & $\begin{array}{l}\text { Carbon emission - } \mathrm{CO}_{2} \\
\text { released per energy } \\
\text { generated, kt } \\
\mathrm{CO}_{2} / \mathrm{GWe}-\mathrm{yr}\end{array}$ & 48.4/B & $34.0 / \mathrm{B}$ & 48.5/B & $33.9 / \mathrm{B}$ \\
\hline & $\begin{array}{l}\text { Radiological exposure, } \\
\text { Sv/GWe-yr }\end{array}$ & B & B & B & B \\
\hline \multirow{2}{*}{ 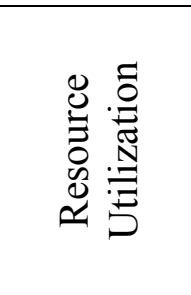 } & $\begin{array}{l}\text { Natural Uranium } \\
\text { required per energy } \\
\text { generated, } t / G W e-y r\end{array}$ & 0/A & 0/A & 0/A & 0/A \\
\hline & $\begin{array}{l}\text { Natural Thorium } \\
\text { required per energy } \\
\text { generated, } t / G W e-y r\end{array}$ & $1.65 / \mathrm{A}$ & $1.52 / \mathrm{A}$ & $1.52 / \mathrm{A}$ & $1.48 / \mathrm{A}$ \\
\hline
\end{tabular}


770 As mentioned, the direct comparisons between the fast spectrum analysis example (SFR

771 with metallic fuel) and the intermediate spectrum examples should be considered

772 carefully before making universal conclusions regarding the tradeoffs between

773 intermediate and fast spectrum designs. However, this study showed that both fast and

774 intermediate spectrum designs for the U3/Th fuel cycle generally yield similar

775 performance in terms of the metrics calculated.

776

777 To isolate the effect of the spectrum on the reactor's breeding (and burnup) performance,

778 a scoping study was performed on the SFR-ThH pin model. The reference 0.5 hydrogen-

779 to-heavy metal ratio of the hydride fuel was adjusted to 0.25 and 0.75 while maintaining

780 the roughly same discharge burnup $(\sim 40 \mathrm{GWd} / \mathrm{t})$. This was done by simultaneously

781 changing the initial ${ }^{233} \mathrm{U}$ content of the SFR-ThH fuel to roughly match this desired

782 burnup level. The results shown in Table 11 clearly indicate that harder spectra for U3/Th

783 fuels produce improved breeding. If another scoping study were performed with the

784 breeding ratio fixed, then the burnup would be expected to increase as the spectrum

785 hardens: ${ }^{233} \mathrm{U}$, like all other fissile materials, has much higher $\eta$ values in the fast energy

786 range. The results from this parametric study indicate that the harder the spectrum, the

787 higher the breeding ratio and/or burnup. Therefore, from a physics point of view, with

788 neutron leakage being equal, the intermediate spectrum systems should offer no breeding

789 or burnup advantages compared to fast spectrum systems. 


\begin{tabular}{|c|l|l|l|l|l|}
\hline $\begin{array}{l}\text { Hydrogen-to- } \\
\text { Heavy Metal } \\
\text { Ratio }\end{array}$ & $\begin{array}{l}\text { \% Fission in } \\
\mathrm{E}<1 \mathrm{eV} \\
(\mathrm{MOL})\end{array}$ & $\begin{array}{l}\% \text { Fission in } \\
\mathrm{eV}-10^{5} \mathrm{eV} \\
(\mathrm{MOL})\end{array}$ & $\begin{array}{l}\% \text { Fission in } \\
10^{5} \mathrm{eV}<\mathrm{E} \\
(\mathrm{MOL})\end{array}$ & $\begin{array}{l}\text { Core Average } \\
\text { Discharge } \\
\text { Burnup (Bd) } \\
{[\mathrm{GWd} / \mathrm{t}]}\end{array}$ & $\begin{array}{l}\text { Fissile } \\
\text { Inventory } \\
\text { Ratio }\end{array}$ \\
\hline 0.25 & $0.53 \%$ & $55.59 \%$ & $43.88 \%$ & 40.02 & 1.12 \\
\hline 0.5 & $2.34 \%$ & $65.70 \%$ & $31.96 \%$ & 40.00 & 0.99 \\
\hline 0.75 & $4.88 \%$ & $69.52 \%$ & $25.61 \%$ & 41.08 & 0.90 \\
\hline
\end{tabular}

794 Although the burnup and breeding performance is dictated by $\eta$, there may be discrete

795 advantages for the intermediate spectrum systems from the perspective of parameters like

796 void coefficient. In this sense, the intermediate spectrum may enable a very low leakage

797 sodium-cooled reactor design because the void worth is reduced. As noted in Zhang and

798 Greenspan (2014), this is due to the relatively constant $\eta$ of ${ }^{233} U$ throughout the

799 intermediate energy regime (lack of positive slope). However, it is noted that it is

800 possible to design fast spectrum thorium reactors with low or negligible void worth

801 (Fiorina et al., 2013). In addition, ${ }^{233} \mathrm{U} \eta$ is greater than 2.0 over many neutron energies,

802 which means that a self-sustaining system is possible with a wide variety of technology

803 options.

804

805 Summary

806

807 Physics analyses were performed for a diverse set of technology options for an

808 intermediate spectrum system deployed in a particular fuel cycle: continuous recycling of

$809 \mathrm{U} 3 / \mathrm{Th}$ in critical reactors with pure fertile thorium feed. The objective was to determine 
810 whether using an intermediate spectrum critical reactor instead of a fast spectrum critical

811 reactor could achieve similar performance in this fuel cycle.

813 This effort included an examination of a broad spectrum of intermediate spectrum reactor

814 technologies in this fuel cycle, and highlights the technology neutral approach of the

815 overall FCT effort. The study showed that there are two classes of intermediate-spectrum

816 systems considered in this study: those that have significant thermal- spectrum

817 contributions to the overall fissions (with a MSR example in this study) and the other

818 types that have significant fast-spectrum contributions (with examples using water, liquid

819 metal coolant, or a heavier moderator being considered in this study). The analyzed

820 examples with intermediate spectrum reactor systems showed very similar performance,

821 in terms of the calculated metrics, as the reference fuel cycle using an example sodium-

822 cooled fast reactor design with metallic fuel.

824 The burnup and breeding performance of intermediate spectrum systems in this fuel cycle

825 will be limited by the lower $\eta$ at intermediate energies versus fast energies. This was

826 confirmed by the parametric scoping calculations that isolated the spectral effects. It is

827 important to note that a comparison between different core designs (a small fast reactor

828 core with high leakage versus large cores with low leakage for the some of the

829 intermediate spectrum technology options) should not be used to make universal

830 conclusions regarding the tradeoffs between fast and intermediate spectra. However, the

831 results of this study indicate that the overall fuel cycle performance is expected to be 
832 similar for fast and intermediate spectrum critical reactors if deployed in this fuel cycle at

833 equilibrium.

834

\section{Acknowledgements}

836 This effort was supported by the U.S. Department of Energy Office of Nuclear Energy

837 (DOE-NE) Fuel Cycle Options Campaign.

838

839 This manuscript has been authored by employees of Brookhaven Science Associates LLC

840 under Contract No. DE-SC0012704 and DE-AC02-98CH10886, Oak Ridge National

841 Laboratory, managed by UT-Battelle LLC under Contract No. DE-AC05-00OR22725,

842 and UChicago Argonne, LLC under Contract No. DE-AC02-06CH11357 with the US

843 Department of Energy. The publisher by accepting the manuscript for publication

844 acknowledges that the United States Government retains a non-exclusive, paid-up,

845 irrevocable, world-wide license to publish or reproduce the published form of this

846 manuscript, or allow others to do so, for United States Government purposes.

\section{References}

850 M. Aufiero, A. Cammi, C. Fiorina, J. Leppanen, L. Luzzi, M. E. Ricotti, “An extended

851 version of the SERPENT-2 code to investigate fuel burnup and core material evolution of

852 the Molten Salt Fast Reactor", Journal of Nuclear Materials 441, pp. 473-486 (2013). 
854 E.S. Bettis and R. C. Robertson, "The Design and Performance Features of a Single-Fluid 855 Molten-Salt Breeder Reactor,” Nucl. App. And Tech. 8 (1970).

856

857 R. C. Briant and A. M. Weinberg, "Molten Fluorides as Power Reactor Fuels," Nuclear 858 Science and Engineering 2, pp. 797-803 (1957).

859

860 N. R. Brown and M. Todosow, "Fuel Cycle Performance of Intermediate Spectrum

861 Reactors with U/Th Feed and Continuous Recycling of U/TRU and Th/U3," ANFM2015

862 - Advances in Nuclear Fuel Management V, Hilton Head, South Carolina, March 29 863 April 1 (2015).

864

865 M.B. Chadwick et al., "ENDF/B-VII.0: Next Generation Evaluated Nuclear Data Library 866 for Nuclear Science and Technology Applications,” Nuclear Data Sheets 107, pp. 29318673060 (2006).

868

869 A.G. Croff, "A User's Manual for the ORIGEN2 Computer Code," ORNL/TM-7175, 870 Oak Ridge National Laboratory (1980).

871

872 K. L. Derstine, "DIF3D: A Code to Solve One-, Two-, and Three-Dimensional Finite 873 Difference Diffusion Theory Problems," ANL-82-64, Argonne National Laboratory $874 \quad$ (1984)

875 
876 T. Downar, A. Hall, D. Jabaay, A. Ward, E. Greenspan, F. Ganda, F. Bartoloni, R.

877 Bergmann, C. Varela, C. DiSanzo, M. Kazimi, A. Karahan, E. Shwageraus, B. Feng, B.

878 Herman, Technical Evaluation of the HITACHI Resource-Renewable BWR (RBWR)

879 Design Concept, Final Report, Electric Power Research Institute Report number 880 1025086, EPRI: Palo-Alto, CA (2012).

881

882 A. E. Dubberlay et al., "Superprism Oxide and Metal Fuel Core Designs," Proceedings of 883 ICONE 8, Baltimore, USA, April 2-6 (2000)

884

885 M. J. Driscoll, T. J. Downar, E. E. Pilat. The Linear Reactivity Model for Nuclear Fuel 886 Management. American Nuclear Society, La Grange Park, Illinois (1990).

888 L. B. Freeman, B. R. Beaudoin, R. A. Frederickson, G. L. Hartfield, H. C. Hecker, S. 889 Milani, W. K. Sarber, W. C. Schick, "Physics experiments and lifetime performance of 890 the light water breeder reactor," Nuclear Science and Engineering 102, pp. 341-364 891 (1989).

892

893 C. Fiorina, N. E. Stauff, F. Franceschini, M.T. Wenner, A. Stanculescu, T.K. Kim, A. 894 Cammi, M.E. Ricotti, R.N. Hill, T.A. Taiwo, M. Salvatores, "Comparative Analysis of 895 Thorium and Uranium Fuel for Transuranic Recycle in a Sodium Cooled Fast Reactor," 896 Annals of Nuclear Energy, Vol. 62, pp. 26-39 (2013). 
898 C. W. Forsberg, "Thermal and Fast-Spectrum Molten Salt Reactors for Actinide Burning 899 and Fuel Production," GLOBAL 2007, Boise, Idaho, 1725-1732, September 9-13 (2007).

900

901 F. Ganda, F. J. Arias, J. Vujic, E. Greenspan, "Self-sustaining thorium boiling water 902 reactors," Sustainability 4, pp. 2472-2497 (2012).

903

904 P. M. Gorman, G. Zhang, J. E. Seifried, C. R. Varela, J. L. Vujic, and E. Greenspan, "The 905 fuel-self-sustaining RBWR-Th core concept and parametric studies," Proceedings of 906 ICAPP 2014, Charlotte, USA, April 6-9 (2014).

907

908 K. Hibi, S. Shimada, T. Okubo, T. Iwamura, S. Wada, "Conceptual designing of reduced909 moderation water reactor with heavy water coolant," Nuclear Engineering and Design $910 \quad 210$, pp. 9-19 (2001).

911

912 J. C. Hopkins and B. C. Diven, "Neutron Capture to Fission Ratios in 233 U, 235 U, 239

913 Pu," Nuclear Science and Engineering, vol. 12, pp. 169-177 (1962).

914

915 Idaho National Laboratory, "Online Nuclear Fuel Cycle Options Catalog," $916<\mathrm{https} / /$ inlportal.inl.gov/portal/server.pt/community/nuclear_science_and_technology/33

917 7/online_nuclear_fuel_cycle_options_catalog>, Accessed October 24 (2014).

918

919 J. Leppänen, M. Pusa, T. Viitanen, V. Valtavirta, T. Kaltiaisenaho, Ann. Nucl. Energy 920 (2014), http://dx.doi.org/10.1016/j.anucene.2014.08.024. 
922 B. A. Lindley, C. Fiorina, F. Franceschini, E. J. Lahoda, G. T. Parks, "Thorium breeder 923 and burner fuel cycles in reduced-moderation LWRs compared to fast reactors," Progress 924 in Nuclear Energy 77, pp. 107-123 (2014).

925

926 Los Alamos National Laboratory, "MCNP-A General Monte Carlo N-Particle Transport

927 Code, Version 5,’ LA-UR-03-1987 (2005).

928

929 Oak Ridge National Laboratory, SCALE: A Comprehensive Modeling and Simulation 930 Suite for Nuclear Safety Analysis and Design, Oak Ridge National Laboratory Technical 931 Report (ORNL/TM-2005/39), June (2011).

932

933 G. T. Parks, J. D. Lewins, Quadratic reactivity fuel-cycle model stability. Annals of 934 Nuclear Energy 14, 145-151 (1987).

935

936 S. Permana, N. Takaki, H. Sekimoto, "Feasible Region of Design Parameters for Water 937 Cooled Thorium Breeder Reactor," Journal of Nuclear Science and Technology 44, pp. $938 \quad 946-957$ (2007).

939

940 S. Permana, N. Takaki, H. Sekimoto, "Preliminary study of large and small water cooled 941 thorium breeder reactor in equilibrium states," Progress in Nuclear Energy 50, pp. 320$942324(2008)$ 
944 J. J. Powers, J. C. Gehin, A. Worrall, T. J. Harrison, E. E. Sunny, “An Inventory Analysis 945 of Thermal-Spectrum Thorium-Fueled Molt Salt Reactor Concepts," Proceedings of 946 PHYSOR2014 - The Role of Reactor Physics Towards a Sustainable Future, The Westin

947 Miyako, Kyoto, Japan, September 28 - October 3, 2014, on CD-ROM (2014).

948

949 J. E. Seifried, P. M. Gorman, J. L. Vujic, and E. Greenspan, “Accelerated Equilibrium 950 Core Composition Search Using a New MCNP-Based Simulator," Proceedings of the 951 SNA\&MC 2013 Conference, Paris, France, October (2013).

952

953 Y. Shaposhnik, E. Shwageraus, and E. Elias, "Core design options for high conversion 954 BWRs operating in the Th- ${ }^{233} \mathrm{U}$ fuel cycle," Nuclear Engineering and Design 263, pp. 955 193-205 (2013).

956

957 Y. Shaposhnik, E. Shwageraus, and E. Elias, "Shutdown margin for high conversion 958 BWRs operating in Th-233U fuel cycle," Nuclear Engineering and Design 276, pp. 162$959177(2014)$

960

961 E. Shwageraus, D. Volasky, E. Fridman, "High Conversion Thorium Fuel Cycle for 962 PWRs," Proceedings of the International Youth Nuclear Congress, Interlaken, 963 Switzerlan, Sept. 20 - 26 (2008). 
965 P. E. Spivak, B. G. Erozolimsky, G. A. Dorofeev, V. N. Lavrenchik, I. E. Kutikov, and 966 Y. P. Dobrynin, Atomnya Energiya 1, pp. 21, 1956. English translation in: J. Nuclear 967 Energy 4, pp. 79, 1957. Data is included in: BNL 325, Volume III, September 1965.

969 N. E. Stauff, T. K. Kim, T. A. Taiwo, "Variations in nuclear waste management 970 performance of various fuel-cycle options," Journal of Nuclear Science and Technology 971 (In press: accepted 14 March 2015).

972

973 N. Takaki and D. Mardiansah, "Core Design and Deployment Strategy of Heavy Water 974 Cooled Sustainable Thorium Reactor," Sustainability 4, pp. 1933-1945 (2012).

975

976 R. Takeda, J. Miwa, and K. Moriya., "BWRs for Long-term Energy Supply and for 977 Fissioning almost all Transuraniums," GLOBAL 2007, Boise, Idaho, 1725-1732, 978 September 9-13 (2007).

979

980 B. J. Toppel, “A User's Guide to the REBUS-3 Fuel Cycle Analysis Capability,” ANL981 83-2, Argonne National Laboratory (1983)

982

983 R. Wigeland, T. Taiwo, H. Ludewig, M. Todosow, W. Halsey, J. Gehin, R. Jubin, J.

984 Buelt, S. Stockinger, K. Jenni, B. Oakley, "Nuclear Fuel Cycle Evaluation and Screening 985 - Final Report," INL/EXT-14-31465 FCRD-FCO-2014-000106, Idaho National 986 Laboratory Technical Report, October 8 (2014). See also: 
987 https://inlportal.inl.gov/portal/server.pt/community/nuclear_science_and technology/337

988 /fuel_cycle_evaluation_and_screening_overview

989

990 Z. Xu, P. Hejzlar, and M.S. Kazimi, "MCODE, Version 2.2-an MCNP-ORIGEN

991 Depletion Program,” MIT-NFC-TR-104, MIT Center for Advanced Nuclear Energy 992 Systems (2006).

993

994 D. Yun, T. A. Taiwo, T. K. Kim, A. Mohamed, "Th/U-233 Multirecycle in Pressurized 995 Water Reactors: Feasibility Study of Multiple Homogeneous and Heterogeneous 996 Assembly Designs," Transactions of the American Nuclear Society 103, pp. 809-810 997 (2010).

998

999 G. Zhang, J. Seifred, J. Vujic, and E. Greenspan, "Variable Enrichment Thorium-Fueled 1000 Boiling Water Breeder Reactor," Transactions of the American Nuclear Society, vol. 108, 1001 pp. 846-848 (2013).

1002

1003 G. Zhang and E. Greenspan, "Feasibility of Thorium-Hydride Fueled Sodium-Cooled 1004 Self-Sustaining Reactors," Transactions of 2014 ANS Winter Meeting, Anaheim, USA, 1005 November 9-13 (2014).

1006 